\title{
BEYOND CASH: ASSESSING EXTERNALITY AND BEHAVIOUR EFFECTS OF NON-EXPERIMENTAL CASH TRANSFERS
}

\section{Rafael Perez Ribas}

University of Illinois at Urbana-Champaign

Fábio Veras Soares

Clarissa Teixeira

International Policy Centre for Inclusive Growth

\section{Elydia Silva}

Brazilian Development Bank (BNDES)

\section{Guilherme Hirata}

Pontifical Catholic University of Rio de Janeiro

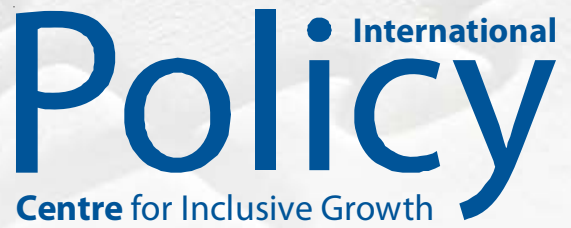




\author{
Copyright $\odot 2010$ \\ International Policy Centre for Inclusive Growth \\ United Nations Development Programme
}

International Policy Centre for Inclusive Growth (IPC - IG)

Poverty Practice, Bureau for Development Policy, UNDP

Esplanada dos Ministérios, Bloco $0,7^{\circ}$ andar

70052-900 Brasilia, DF - Brazil

Telephone: +556121055000

E-mail: ipc@ipc-undp.org • URL: www.ipc-undp.org

The International Policy Centre for Inclusive Growth is jointly supported by the Poverty Practice, Bureau for Development Policy, UNDP and the Government of Brazil.

\title{
Rights and Permissions
}

All rights reserved.

The text and data in this publication may be reproduced as long as the source is cited. Reproductions for commercial purposes are forbidden.

The International Policy Centre for Inclusive Growth disseminates the findings of its work in progress to encourage the exchange of ideas about development issues. The papers are signed by the authors and should be cited accordingly. The findings, interpretations, and conclusions that they express are those of the authors and not necessarily those of the United Nations Development Programme or the Government of Brazil.

Working Papers are available online at www.ipc-undp.org and subscriptions can be requested by email to ipc@ipc-undp.org 


\title{
BEYOND CASH: ASSESSING EXTERNALITY AND BEHAVIOUR EFFECTS OF NON-EXPERIMENTAL CASH TRANSFERS*
}

\author{
Rafael Perez Ribas, ${ }^{* *}$ Fábio Veras Soares, ${ }^{* * *}$ Clarissa Teixeira, ${ }^{* * *}$ \\ Elydia Silva, ${ }^{* * * *}$ and Guilherme Hirata, ${ }^{* * * * *}$
}

\begin{abstract}
In this paper we propose a method to estimate externality effects in cash transfer programmes, even in cases when the benefit is not randomly assigned. Externality is assessed through the decomposition of the average treatment effect on the treated (ATT) into participation (direct) effect and externality (indirect) effect. We also suggest a nonparametric decomposition to investigate whether changes in household outcomes are caused by the income transfer itself or by the other non-monetary components of the programme, such as conditionalities and family support services. We apply all these decompositions on the effect of a conditional cash transfer (CCT) programme on household consumption and savings in Paraguay. This was possible because of the presence of two distinct comparison groups, one within the village and potentially exposed to the externality, and another in a different village not affected by the programme. Furthermore, the evaluation survey collected information on both income and consumption. The results indicate that the programme has a small impact on consumption and a considerable impact on savings. In the absence of externality, however, the programme would have a higher effect on consumption, mostly associated with the cash transfer, and a lower effect on savings. Moreover, the impact on the pattern of consumption is significantly related to a substitution effect and is not related to the increase in income.
\end{abstract}

Keywords: Externality, Income Effect, Behaviour Effect, Conditional Cash Transfer.

JEL Classification: C21, D12, D62, 138.

\footnotetext{
* We gratefully acknowledge financial and scientific support from the Poverty and Economic Policy (PEP) Research Network, which is financed by the Australian Agency for International Development (AusAID) and by the Government of Canada through the International Development Research Centre (IDRC) and the Canadian International Development Agency (CIDA). We are particularly grateful to Habiba Djebbari, Chris Ryan, Maria Laura Alzua, PIERI Steering Committee, and participants in the Seventh PEP General Meeting, in the 3ie/AfrEA Perspectives on Impact Evaluation Meeting, and in seminars at Ipea-Rio and Ipea-Brasília. The views, findings and recommendations expressed in this publication, however, are those of their authors alone. They do not necessarily represent the views of UNDP, its Executive Board or the UN Member States.

** University of Illinois at Urbana-Champaign.

*** International Policy Centre for Inclusive Growth.

**** Brazilian Development Bank (BNDES).

***** Pontifical Catholic University of Rio de Janeiro.
} 


\section{INTRODUCTION}

Since the mid 1990s, conditional cash transfer (CCT) programmes have become quite popular among policymakers and policy advisers as effective and efficient means of reducing poverty in developing countries, mainly in Latin America. Currently, most countries in the region have some sort of CCT programme, including Mexico, Brazil, Colombia, Honduras, Panama, Peru, Paraguay, Guatemala, El Salvador, the Dominican Republic, Chile, Uruguay, Argentina and Costa Rica.

These programmes aim to alleviate poverty in the short run through the cash transfer, and to break the intergenerational transmission of poverty by fostering the accumulation of human capital. Hence they are based not only on income distribution but also on certain actions that households are required to take in order to receive the transfer. These actions, known as conditionalities or co-responsibilities, are usually related to children's attendance at school, regular visits to health centres by pregnant women and children, and the updating of immunisation cards. Some programmes also include family support initiatives that seek to promote autonomous income generation on the part of beneficiary households, as well as their social participation. Therefore, these programmes intend to reduce poverty not only by increasing household income but also by changing the behaviour of poor families.

Impact evaluations of CCT programmes in Latin America have revealed positive results in several dimensions. ${ }^{1}$ Because of the way in which these evaluations are designed, however (even experimental assessments such as those undertaken for PROGRESA in Mexico $^{2}$ and the Red de Protección Social (RPS) in Nicaragua), one cannot disentangle in any simple way what can be attributed to the effect of the transfer itself and what is due to behavioural changes linked to the conditionalities, as well as to other programme components. Additionally, few studies have examined the externalities of CCT programmes. Externalities are likely to be present in such contexts because of the learning processes fostered by social interactions between beneficiaries and non-beneficiaries, and because of general equilibrium effects that influence local prices.

Understanding the impact of the conditionalities and the existence of externalities is an important step in reaching a better assessment of the black-box results of standard impact evaluations, and in providing policymakers with better information on the adequacy of their CCT programmes. Handa et al. (2009) mention that programme components such as conditionalities, which do not have a significant effect, may entail unnecessary costs, ${ }^{3}$ whereas Lalive and Cattaneo (2009) point out that if there are externalities, the targeting of programmes matters for their effect.

This paper puts forward a methodology that aims to address both the estimation of externality effects and the full decomposition of the programme's impact into income effect and behavioural-change effect for cases where an experimental design is not necessarily available. The externality effect is basically handled with a multiple-treatment approach, like those proposed by Imbens (2000), Lechner (2001), and Hudgens and Halloran (2008). ${ }^{4}$ The decomposition of the average treatment effect is based on a semi-parametric approach, as in DiNardo et al. (1996), which avoids misunderstandings caused by some kind of linearity. In particular, and in contrast to Hoddinott and Skoufias (2004), Rubalcava et al. (2004), Gitter and Barham (2007), and Handa et al. (2009), the income expansion path is estimated nonparametrically and it guarantees that the identified behavioural-change effect does not come from the change in household income. 
The data are from a household survey designed for the impact evaluation of the pilot phase of the Tekoporã programme in Paraguay. In addition, we used data from the programme's administrative records, which include the payment accounts, and from the Ficha Hogar, a small questionnaire used to gather information for the purposes of selecting beneficiary households. Using all these data we estimate the effect of Tekoporã on households' consumption and savings.

All the estimates and decompositions in this paper are made for the parameter of average treatment effect on the treated (ATT). It is worth mentioning that our methodology can be applied to both experimental and quasi-experimental designs, but the meaning of externality and the interpretation of the ATT estimates vary according to the comparison group being used. Angelucci and De Giorgi (2009), for instance, analyse the externality effect only on households that are not eligible to participate in PROGRESA. It is plausible, however, that externalities can also affect treated households. Thus, even when all households are covered by the programme, there is some externality that can either boost or attenuate its expected impact.

For this reason, we decompose the ATT into two components: the average participation effect on the treated (APT) and the average externality effect on the treated (AET). We also decompose each of these effects into three components: income effect, substitution effect, and unexplained effect. That is, changes in consumption can arise from changes in household income, marginal propensity to consume, or idiosyncratic autonomous consumption.

The combination of the latter two effects can be regarded as a behavioural effect. ${ }^{5}$

The results point to the presence of programme externalities within communities. If there were no interaction between households, the programme would increase treated households' consumption by 21 per cent and their savings by 31 per cent. These direct effects of participation are found to be strictly associated with the rise in income generated by the transfers. That is, an unconditional transfer would cause the same increase in household consumption and savings as the programme did. However, the indirect impact caused by externality attenuates the direct impact on consumption and boosts the direct impact on savings. Moreover, these indirect effects are entirely associated with changes in household behaviour according to our proposed decomposition. Finally, the income component of the programme has no effect on the consumption composition of treated household. Hence an unconditional transfer might not be effective in changing the consumption pattern of poor households.

Besides this introduction, this paper contains five other sections. The second section presents a brief review of the literature. The third describes the main features of Tekoporã and the sampling design of its evaluation, emphasising how the comparison groups are defined. The fourth section puts forward the methodology used to decompose the ATT into participation effect and externality effect, as well as the decomposition into income and behavioural-change effects. The fifth section presents the main results in terms of household consumption and savings. The sixth section presents the conclusions.

\section{WHY MIGHT THE EFFECT OF CCT PROGRAMMES GO BEYOND INCOME TRANSFER?}

The main difference between unconditional and conditional cash transfer programmes is that the former only seek to relax poor households' budget constraint, while the latter also seek to 
change the households' behaviour in terms of budget and time allocations. That is, while it is expected that unconditional programmes only have an income effect on the outcome of interest, one may expect that conditional programmes have both an income effect and a substitution effect; the sum of these two effects gives the total effect of the programme. ${ }^{6}$ Thus it should be expected that the conditional transfer is not like other ordinary incomes, having a distinct effect on household decisions.

Hoddinott and Skoufias (2004), for instance, state that the income effect itself explains about 50 per cent of the total positive impact on consumption found in the PROGRESA evaluation. The remaining impact might be attributed to one of the conditionalities of the programme: attendance at talks on health issues (pláticas). ${ }^{7}$ They also show that PROGRESA had a positive externality effect on non-beneficiaries' acquisition of calories from fruits, vegetables and animal products. Then they speculate that the information provided by pláticas may have spilled over to non-beneficiaries.

Like Hoddinott and Skoufias in Mexico, Attanasio and Mesnard (2006), Maluccio and Flores (2005), Schady (2006) and Oliveira et al. (2007) show that CCT programmes have changed the consumption basket of households in Colombia, Nicaragua, Ecuador and Brazil, respectively. In Colombia and Nicaragua, Attanasio and Mesnard, and Maluccio and Flores, find that the food consumption of beneficiary households grew as much as their aggregate consumption, which may be more than the Engel curve predicts. On the basis of results obtained by Adato and Roopnaraine (2004, apud Maluccio and Flores, 2005), Maluccio and Flores presume that part of the impact of RPS on food consumption stems from the fact that some community agents (promotoras) frequently ask beneficiaries to show purchase receipts after transfers have been made. In Ecuador and Brazil, Schady, and Oliveira et al., show that the programmes have affected the expenditure share of households, even though there is no significant impact on aggregate level of consumption.

All this evidence suggests that CCT programmes have had significant impacts on the Engel curve of beneficiary households. Specifically, these households have been encouraged by the programmes to change their behaviour in terms of consumption patterns. Such evidence may distinguish CCT programmes from other types of targeted cash transfers, whose benefitaccording to Case and Deaton (1998) and Edmonds (2002) - is shown to be used like other income by households. ${ }^{8}$

Besides those reasons suggested by Hoddinott and Skoufias (the effect of pláticas) and Maluccio and Flores (the effect of promotoras), there are some other explanations for the behaviour effect of CCT programmes. The first explanation is that these programmes are usually female-based, giving preference to the mother to receive the transfer. ${ }^{9}$ According to Attanasio and Lechene (2002) and Schady and Rosero (2007) respectively, both PROGRESA in Mexico and the Bono de Desarrollo Humano (BDH) in Ecuador have improved the bargaining position of women in beneficiary households, giving them greater capacity to influence decisions on expenditures. These authors, along with Rubalcava et al. (2004), show that the programmes have consequently changed the households' consumption pattern toward goods that benefit children, since more money is in the hands of women.

Although Handa et al. (2009) confirm that PROGRESA has improved the bargaining position of some women, they do not find that this improvement has a significant effect on household consumption. Similarly, Gitter and Barham (2007) do not find evidence that the impact of Nicaragua's RPS on school enrolment and expenditures is driven by the greater power of women 
in their households. They find that the CCT benefit has an effect on schooling which is significantly higher than the effect of other earnings. In Mexico, Rubalcava et al. (2004) also show that the effect of the CCT benefit on the expenditure shares of education, child clothing and meat is significantly higher than the effect of a general income increase. Gitter and Barham, as well as Rubalcava et al., suggest that the differentiated elasticity of the CCT benefit derived not only from the change in intra-household bargaining power but also from other programme components, such as conditionalities and complementary initiatives. ${ }^{10}$

By estimating a similar model, Handa et al. (2009) seem to contradict the findings of Rubalcava et al. (2004). Handa et al. show that the PROGRESA benefit has no effect on education spending and makes no difference in terms of child clothing with respect to other earnings. Hence they conclude that the PROGRESA transfer is treated as general income by the households and its effects would not differ from those of an unconditional transfer. It is worth mentioning, however, that there are some critical differences between the models of Handa et al. and Rubalcava et al. The former authors use instrumental variables to predict both the per capita transfer and per capita income, ${ }^{11}$ estimate the effects on expenditure levels, and adopt a linear model with constant elasticities. The latter authors are not concerned about any source of endogeneity, estimate the effects on expenditure shares, and adopt a non-linear model with a flexible spline. Regarding this latter point, Rubalcava et al. actually show that ignoring nonlinearities in the income effect could lead to misleading results.

To test the role of conditionalities, Ruiz-Arranz et al. (2006) compare the effects of PROGRESA with PROCAMPO, another cash transfer programme in Mexico that benefits male farmers and whose conditionality is linked to agricultural production. They conclude that, on the one hand, cash transfers related to production increase food security through productive investments and have a higher impact on the probability of households eating meat and fish. On the other hand, cash transfers related to human capital investments have the same effect on food security, but by means of market purchases, and a higher effect on the probability of consuming fruits, vegetables, dairy products and processed foods.

The most evident and precise testing for the importance of conditionalities on CCT programmes is probably that of de Brauw and Hoddinott (2007). They take advantage of the fact that some beneficiaries of PROGRESA did not receive the forms needed to monitor their children's attendance at school. Then they show that the absence of monitoring significantly reduces the probability of school attendance, particularly in the transition from primary to secondary school. This result is similar to that obtained by Bourguignon et al. (2003) for Bolsa Escola in Brazil. The difference is that Bourguignon et al. adopt an ex-ante impact evaluation approach but they also identify a strong effect of conditionality on school attendance, in contrast to a muted effect of the transfer on current poverty. Since the conditionality has an effect on schooling, it may also affect other allocation decisions within treated households.

As regards the externalities of CCT programmes, Angelucci and De Giorgi (2009) present a clear result that PROGRESA has had a positive impact on the food consumption of households that are ineligible for the programme. This impact, however, is not caused by a higher demand in the local economies and a consequent rise in the ineligibles' earnings. That indirect effect is related to risk-sharing promoted by community-level networks. They argue that the programme has increased food consumption by means of loans and transfers from eligible to ineligible households. Furthermore, Angelucci et al. (2009) explicitly show that this indirect effect on consumption is significant only among ineligible households embedded in family networks. 
Bobonis and Finan (2009) and Lalive and Cattaneo (2009) show that PROGRESA has also had positive externality effects on school enrolment and attendance, respectively. Their hypothesis is that externalities are promoted by endogenous peer effects as a result of social interaction between beneficiaries and non-beneficiaries. In the case of Bobonis and Finan, the closer the child's household is to the eligibility cut-off point, the higher the peer effect. Lalive and Cattaneo, however, highlight that peer effects also affect eligible children, boosting the impact of the programme. Moreover, they claim that peer effects arise because parents learn from each other about the ability of their children. ${ }^{12}$

Since CCT programmes also have significant impacts on health (Gertler, 2004; Attanasio et al., 2005), this might be another source of externality, one that affects the outcome of nonbeneficiary households by reducing epidemics in the population as a whole. Miguel and Kremer (2004), for instance, show that deworming treatment reduces worm burdens and then increases school attendance among both treated and untreated children in Kenya. Finally, another hypothesis for the presence of externalities in CCT programmes is that given the lack of understanding about how eligibility is defined, some households may emulate the behaviour of the beneficiaries in an attempt to show that they too could qualify for the programme.

\section{PROGRAMME DESCRIPTION AND EVALUATION DESIGN}

\subsection{THE PILOT OF THE TEKOPORÃ PROGRAMME}

Tekoporã is a CCT programme that has been scaled up in Paraguay. Like other CCT programmes, it was designed in the context of a national strategy to fight poverty, as part of the general effort to meet the Millennium Development Goals (MDGs). The programme seeks to reduce extreme poverty by giving direct cash transfers to poor households with children, and to lessen potential future poverty by encouraging investments in human and social capital. The transfers are conditional on school attendance, regular visits to health centres and periodic immunisations. The programme also includes a family support component that, among other objectives, should increase the household's productive capacity and social participation. ${ }^{13}$

The pilot programme consisted of a monthly transfer to extremely poor families in rural areas with children up to the age of 15 and/or a pregnant woman. These households were entitled to a benefit of 30,000 guaranies (US\$ 6) per child or pregnant woman up to a limit of four children per household; this was in addition to a basic transfer of 60,000 guaranies (US\$12) per month. Eligible households could thus receive between 90,000 and 180,000 guaranies per month (US\$ 18 and US\$36). ${ }^{14}$

The pilot started in 2005, covering about 4,500 households in five districts of two departments: Buena Vista and Abai in the Department of Caazapá, and Santa Rosa del Aguaray, Lima and Union in the Department of San Pedro. The first payments were made in Buena Vista in September 2005. By August 2006, the pilot covered 4,324 beneficiary households in those five districts. Tekoporã has been gradually expanded, and reached 15 districts in five departments by 2009 . These districts were selected from a pool of 66 considered to contain the bulk of the vulnerable population, according to a scoring index called the Geographical Prioritisation Index (IPG), which is composed of both monetary and non-monetary indicators. 
To identify eligible households, a non-monetary quality of life index (ICV) was adopted as the targeting tool. Such an approach has been common throughout Latin America, where poverty monitoring often relies on a composite index of unsatisfied basic needs. The ICV varies between zero and 100 and is composed of variables related to housing conditions; access to public services and utilities such as water, electricity, garbage collection and telephone; healthcare and insurance; the education of the head of household and spouse; school achievement of children aged between six and 24; the occupation of the head of the household; ownership of durable goods; and the household's demographic composition. Unlike the IPG, the ICV does not use any monetary variables.

Households are eligible for the programme if they meet all of the following conditions: (1) have children under 15 years of age or pregnant women; (2) live in the priority areas of the programme, namely the poorest districts in the country according to the IPG; and (3) have an ICV of below 40 points. $^{15}$

\subsection{DATABASE}

In the absence of a baseline survey, information on household characteristics before the programme started comes from the database originated by Ficha Hogar, which was the instrument used to collect information on the variables used to calculate the ICV - the main indicator for the selection of beneficiary households.

In this pilot phase, the Ficha Hogar was fielded through a census in the poorest areas of the selected districts, in addition to the poorest areas of two other districts-Moises Bertoni in the department of Caazapá, and Tucuati in the department of San Pedro-that did not take part in the pilot. Furthermore, potentially eligible households that were not in the poorest areas of the districts for the pilot could also be included in the programme registry as a result of the so-called "demand process"-namely, on the basis of their demand to have information on their living conditions provided to the Ficha Hogar. In total, 7,990 households were screened by the census and 1,827 by demand.

The evaluation survey went to the field between January and April 2007, based on a sample of 1,401 households derived from the Ficha Hogar. The response rate of the survey was 78 per cent - that is, 1,089 households were actually interviewed. The questionnaire used in the follow-up survey encompassed all the information available in the Ficha Hogar, in order to reproduce the baseline information. It also included important questions related to outcome indicators that were not covered by the Ficha Hogarsuch as consumption and school attendance-and it had a module on the beneficiaries' perception of the programme.

\subsection{COMPARISON GROUP}

In any impact evaluation, the comparison group must be as similar as possible to the beneficiary (or treated) group except that it does not participate in the programme. For Tekoporã, it was possible to identify two comparison groups: (1) non-beneficiaries living in the other two districts covered by the census (Ficha Hogar) but not by the pilot project; and (2) non-beneficiaries living in the same five districts as the beneficiaries. Furthermore, both groups of households were divided into eligibles (which had children and an ICV below 40) and ineligibles (which also had children but with an ICV equal to or greater than 40). Households that did not have children or pregnant women were automatically excluded from the dataset, as were those households that registered with an incomplete interview. ${ }^{16}$ 
Table 1 presents the reasons for the non-participation in the programme of the potential comparison group in the Ficha Hogar database. The largest group comprises households in the two districts not participating in the pilot (39 per cent). In these districts, more than 90 per cent $(1,160$ of 1,284$)$ of the households with children had an ICV below 40 . It is worth mentioning that those two districts were meant to be included in the pilot, but because of budget constraints the programme could only cover five districts. To keep the geographical balance between departments, one district from each department was excluded from the pilot.

The second largest group of non-beneficiaries consists of households that lived in the districts of the pilot but were "overlooked" or "forgotten" by the programme (35 per cent). In this case, about 66 per cent (542 of 708) were eligible for the programme (ICV below 40). One possible reason for this administrative error is related to the change in the cut-off point of the eligibility criteria. As the cut-off point was increased from 25 to 40 when registration for the programme had already begun, it is possible that in some neighbourhoods, potential beneficiaries whose ICV was between 25 and 40 did not receive an invitation to register.

TABLE 1

Reasons for Not Receiving the Treatment

\begin{tabular}{|c|c|c|c|c|c|c|}
\hline & $\begin{array}{l}\text { Eligible } \\
\text { ICV<40 }\end{array}$ & $\%$ & $\begin{array}{l}\text { Ineligible } \\
\text { ICV }>40\end{array}$ & $\%$ & Total & $\%$ \\
\hline Districts excluded from the pilot & 1,160 & 44.24 & 124 & 17.71 & 1,284 & 38.65 \\
\hline Overlooked & 776 & 29.60 & 398 & 56.86 & 1,174 & 35.34 \\
\hline Rejected by selection committee ${ }^{17}$ & 542 & 20.67 & 166 & 23.71 & 708 & 21.31 \\
\hline Waiting for landless movement permission & 127 & 4.84 & 12 & 1.71 & 139 & 4.18 \\
\hline Graduated due to economic autonomy & 17 & 0.65 & 0 & 0.00 & 17 & 0.51 \\
\hline Total & 2,622 & 100.00 & 700 & 100.00 & 3,322 & 100.00 \\
\hline
\end{tabular}

Source: Ficha Hogar and payment register of Tekoporã.

The other reasons provided in Table 1 are related to: (1) rejection by the selection committees, whose function was to double-check the list of potential beneficiaries yielded by the ICV ranking; (2) potential beneficiaries living in settlements controlled by the landless movement, who were waiting for permission from their leaders to take part in the programme; and (3) households that were identified as non-poor (because of their degree of economic autonomy) in later checks.

We chose to use the two largest groups of untreated households as our comparison groups in this evaluation - that is, households in districts outside the pilot and households overlooked by the programme. This allows us to make two types of comparison in the impact estimation: "between-district" and "within-district". The other groups were excluded from the evaluation because they were not treated owing to specific unobservable (or hard-to-control-for) reasons.

Thus it was possible to define four types of comparison groups registered in the dataset. These groups consist of eligible and ineligible households in both districts - with and without the programme. Note that the districts excluded from the pilot are neither geographically concentrated nor distinct from the participating districts. Table 2 confirms that, in general, there are no great differences between them. 
TABLE 2

Socioeconomic Conditions of Districts Screened by the Ficha Hogar

\begin{tabular}{|c|c|c|c|}
\hline & \multicolumn{2}{|c|}{ Districts } & \multirow[b]{2}{*}{ Total } \\
\hline & In the pilot & Excluded from the pilot & \\
\hline Mean ICV & 27.56 & 29.87 & 29.39 \\
\hline$\%$ ICV less than 25 & 52.72 & 46.57 & 47.84 \\
\hline$\%$ ICV between 25 and 40 & 32.71 & 33.32 & 33.20 \\
\hline$\%$ ICV between 40 and 55 & 9.92 & 11.91 & 11.50 \\
\hline$\%$ ICV greater than 55 & 4.66 & 8.20 & 7.46 \\
\hline Mean household income (in Gs) & $417,820.80$ & $432,534.00$ & $429,482.10$ \\
\hline Mean per capita income (in Gs) & $94,401.44$ & $109,554.10$ & $106,411.10$ \\
\hline$\%$ of (monetarily) poor & 82.10 & 81.08 & 81.29 \\
\hline$\%$ of (monetarily) extremely poor & 69.41 & 70.09 & 69.95 \\
\hline Number of observations ${ }^{*}$ & 6,320 & 1,654 & 7,974 \\
\hline
\end{tabular}

Source: Ficha Hogar.

Note: ${ }^{*}$ all households with complete interview in the census.

\section{METHODOLOGY}

\subsection{ESTIMATION STRATEGY}

In order to measure the programme's impact on an observable outcome, we need to estimate the difference between the outcome with the treatment (participating in the programme) and the outcome without the treatment (not participating) for the same household. When these differences are calculated for all treated households under the necessary conditions, we can obtain the ATT.

Formally, assume that $T_{i}=1$ indicates that the treatment, or programme benefit, is offered to household $i$ and $T_{i}=0$, otherwise. Similarly, $Y_{i}\left(T_{i}=0\right)$ would indicate the outcome of interest for household $i$ when the treatment is not offered, whereas $Y_{i}\left(T_{i}=1\right)$ would be the outcome for household $i$ receiving the programme benefit. Then, the effect of intention to treat on the treated (ITT) can be defined as (Heckman et al., 1999):

$$
\tau_{\text {ITT }}=E\left[Y_{i}\left(T_{i}=1\right)-Y_{i}\left(T_{i}=0\right) \mid T_{i}=1\right],
$$

where $E[$.$] is the expectation function.$

However, we cannot observe the same household in both states (participating and not participating) at same time. Thus we may assume that the outcome in the absence of treatment is orthogonal between the treatment and comparison groups. This can be assumed if the treatment is randomly assigned. Otherwise, a weaker condition, in which the conditional outcome in the absence of treatment is orthogonal to the treatment assignment, should be assumed:

$$
T_{i} \perp\left(Y_{i}\left(T_{i}=0\right), Y_{i}\left(T_{i}=1\right)\right) \mid X_{i},
$$


where $X_{i}$ is a vector of observable characteristics. This assumption implies that, given $X_{i}$, the other unobservable variables, say $Z_{i}$, which determine the treatment assignment, $T_{i}$, are orthogonal to the conditional outcome, $Y_{i} \mid X_{i}, T_{i}$. Thus conditioning on $X_{i}$, one can consistently estimate the ITT parameter by comparing the outcomes of treatment and comparison groups (Rubin, 1978; Rosenbaum and Rubin, 1983).

On the other hand, the ITT estimate will be a consistent estimator for the ATT effect only if the treatment assignment, or intention of treatment, is perfectly correlated with the actual treatment. Thus even when condition (4.2) of selection on observables holds, we should also assume that there are no contamination or externality effects spilling over onto the control group, no alternative treatment offered to the control group, and no drop-out from the treatment group (Heckman et al., 1999; Miguel and Kremer, 2004; Sobel, 2006; Rosenbaum, 2007; Hudgens and Halloran, 2008). This assumption is what Rubin $(1980,1986)$ calls Stable-UnitTreatment-Value Assumption (SUTVA).

In the case of CCT programmes, drop-out from the treatment group is not a large problem because usually there are very few households that do not accept the benefit. Non-compliance with the conditionalities is a more common problem, but its effect is implicit when one evaluates a programme's effectiveness. Neither is the existence of alternative treatment a significant problem, since its beneficiaries are usually either included in the treatment group or excluded from the sample.

Externality of the treatment, however, is indeed an issue to be considered, for two reasons. The first is the contamination of the control group, which can bias the ATT estimates. If we did not distinguish the comparison group between those living in treated communities and those living in other communities, the SUTVA would be violated - that is, the comparison group would be contaminated by households that have also been affected by the programme. The second reason for estimating externality is the interest in assessing its effect, in order to gain a better understanding of the role of social interactions in the programme's effectiveness.

\subsubsection{Assessing Participation and Externality Effects}

In order to identify and disentangle the externality effect, we need to distinguish between the two comparison groups: those in treated communities and those in untreated communities.

Let $D_{i}=1$ indicate that household $i$ living in the area where the programme took place, and $D_{i}=0$ otherwise. Thus, $\left(D_{i}=1, T_{i}=0\right)$ indicates the "within-community" comparison group, while $\left(D_{i}=0, T_{i}=0\right)$ indicates the "between-community" comparison group. For all treated households, $D_{i}$ is certainly equal to one, which leads to $\left(D_{i}=1, T_{i}=1\right)$. Note that there is no treated household in untreated communities, $\left(D_{i}=0, T_{i}=1\right)$, but this counterfactual case is estimated under some identification assumptions.

An underling assumption is that externalities only take place in communities participating in the programme-that is, there is no spillover between communities. Then the average participation effect on the treated (APT), which represents the effect of the programme when there is no externality, is given by: ${ }^{18}$

$\tau_{p}=E\left[Y_{i}\left(D_{i}=0, T_{i}=1\right)-Y_{i}\left(D_{i}=0, T_{i}=0\right) \mid T_{i}=1\right]$, 
whereas the average externality effect on the treated (AET), which represents only the effect of the externalities promoted by the programme, is given by:

$\tau_{e}=E\left[Y_{i}\left(D_{i}=1, T_{i}=0\right)-Y_{i}\left(D_{i}=0, T_{i}=0\right) \mid T_{i}=1\right]$.

We can represent the outcome by the following linear function:

$Y_{i}\left(D_{i}, T_{i}\right)=\alpha+\tau_{p} T_{i}+\tau_{e} D_{i}+\varepsilon_{i}$

This function form assumes that there is no specific effect stemming from the interaction between participation and externality. That is, the externality effect is equal in both cases when the household is treated and when it is untreated; likewise, the participation effect is the same regardless of the existence of externalities. This assumption facilitates the decomposition of the ATT effect, because it implies that

$Y_{i}\left(D_{i}=1, T_{i}=1\right)=Y_{i}\left(D_{i}=0, T_{i}=1\right)+Y_{i}\left(D_{i}=1, T_{i}=0\right)-Y_{i}\left(D_{i}=0, T_{i}=0\right)$.

Moreover, it seems to be more reasonable than the assumption that the externality effect on the treatment group is null.

Then the ATT effect, which represents the total effect of the programme on treated households, is given by the sum of both effects (4.3) and (4.4). Using (4.6) we can write it as:

$$
\begin{aligned}
& \tau_{A T T}=\tau_{e}+\tau_{p} \\
& =E\left[\begin{array}{l}
Y_{i}\left(D_{i}=0, T_{i}=1\right)-Y_{i}\left(D_{i}=0, T_{i}=0\right) \\
+Y_{i}\left(D_{i}=1, T_{i}=0\right)-Y_{i}\left(D_{i}=0, T_{i}=0\right)
\end{array} \mid T_{i}=1\right] \\
& =E\left[Y_{i}\left(D_{i}=1, T_{i}=1\right)-Y_{i}\left(D_{i}=0, T_{i}=0\right) \mid T_{i}=1\right] \text {, }
\end{aligned}
$$

One condition for the identification of these effects is the following orthogonally assumption:

$$
T_{i} \perp\left(Y_{i}\left(T_{i}=0\right), Y_{i}\left(T_{i}=1\right)\right) \mid X_{i}, D_{i} .
$$

It means that the treatment assignment and the potential outcomes are independent conditional on the pre-treatment observed variables, $X_{i}$, and the community, $D_{i}$.

Similarly, we should also assume that the community choice is orthogonal to the potential outcomes conditioned on the observed variables, $X_{i}$, and the household treatment assignment, $T_{i}$ :

$D_{i} \perp\left(Y_{i}\left(D_{i}=0\right), Y_{i}\left(D_{i}=1\right)\right) \mid X_{i}, T_{i}$. 
Since one actually only observes

$Y_{i}=T_{i} \cdot Y_{i}\left(D_{i}=1, T_{i}=1\right)+\left(1-T_{i}\right) \cdot D_{i} \cdot Y_{i}\left(D_{i}=1, T_{i}=0\right)+\left(1-D_{i}\right) \cdot Y_{i}\left(D_{i}=0, T_{i}=0\right)$, assumptions (4.8) and (4.9) are required to guarantee a consistent approximation of the counterfactual, missing, potential outcomes, and then make the following equalities hold:

$$
\begin{aligned}
& \tau_{p}=E\left[Y_{i} \mid X_{i}, D_{i}=1, T_{i}=1\right]-E\left[Y_{i} \mid X_{i}, D_{i}=1, T_{i}=0\right] \\
& \tau_{e}=E\left[Y_{i} \mid X_{i}, D_{i}=1, T_{i}=0\right]-E\left[Y_{\dot{i}} \mid X_{i}, D_{i}=0, T_{i}=0\right], \text { and } \\
& \tau_{A T T}=E\left[Y_{i} \mid X_{i}, D_{i}=1, T_{i}=1\right]-E\left[Y_{i} \mid X_{i}, D_{i}=0, T_{i}=0\right] .
\end{aligned}
$$

One way to obtain those estimators is approximating the conditional means by estimating the following linear function (Rubin, 1977): ${ }^{19}$

$$
\begin{aligned}
Y_{i}= & \alpha_{0}+\tau_{p} T_{i}+\tau_{e} D_{i}+\alpha_{1}^{\prime} X_{i} \\
& +\alpha_{2}^{\prime}\left[X_{i}-E\left(X_{i} \mid T_{i}=1\right)\right] \cdot T_{i}+\alpha_{3}^{\prime}\left[X_{i}-E\left(X_{i} \mid T_{i}=1\right)\right] \cdot D_{i}+\varepsilon_{i} .
\end{aligned}
$$

However, if the dimension of $X_{i}$ is too large and some critical covariates are possibly correlated with the errors in the equations above, it may be difficult to estimate this regression function accurately.

The well-known solution to control for treatment selection on many observable characteristics is to reduce the set of covariates, $X_{i}$, to a scalar by means of a first-stage estimation. That is, we can estimate a propensity score, $p\left(X_{i}\right)=P\left[T_{i}=1 \mid X_{i}\right]$, which represents the probability of household $i$ being treated conditional on $X_{i}$. Given assumption (4.2), treatment assignment, $T_{i}$, and the potential outcomes, $Y_{i}\left(T_{i}\right)$, will also be independent conditional on $p\left(X_{i}\right)$ (Rosenbaum and Rubin, 1983).

The implementation of the propensity score, however, requires an additional assumption:

$$
x_{i} \mid p\left(X_{i}\right) \perp T_{i} \quad \forall x_{i} \in X_{i} .
$$

This assumption is called the "balancing property" and can be empirically verified. Yet in the case of distinct comparison groups or multiple treatments, the balancing property is not as simple as the conventional (Lechner, 2001). The treatment group must be balanced to both the withincommunity comparison group and the between-community comparison group.

Moreover, condition (4.9) requires that we estimate not only the probability of each unit sample being treated but also the probabilities of belonging to the between- and withincommunity comparison groups. These probabilities can be estimated using a multinomial or multivariate regression model, where the probability of being in within-community comparison group, $e\left(X_{i}\right)=P\left[D_{i}=1, T_{i}=0 \mid X_{i}\right]$, is also calculated.

In the second stage, adjusting for the propensity score removes the bias associated with differences in the observed covariates in the treated and comparison groups (Heckman et. al., 1997; Dehejia and Wahba, 2002). One approach, based on Horvitz and Thompson's (1952) theorem, consists of weighting treated and comparison observations to make them 
representative of the population of interest-in our case, the treatment group (Hahn, 1998; Hirano et al., 2003). In this approach, we characterise $\tau_{p}, \tau_{e}$ and $\tau_{A T T}$ through the following moment equations, respectively:

$$
\begin{aligned}
& E\left[p\left(X_{i}\right) \frac{T_{i} \cdot Y_{i}}{p\left(X_{i}\right)}-p\left(X_{i}\right) \frac{\left(1-T_{i}\right) \cdot D_{i} \cdot Y_{i}}{e\left(X_{i}\right)}-\tau_{p}\right]=0, \\
& E\left[p\left(X_{i}\right) \frac{\left(1-T_{i}\right) \cdot D_{i} \cdot Y_{i}}{e\left(X_{i}\right)}-p\left(X_{i}\right) \frac{\left(1-D_{i}\right) \cdot Y_{i}}{1-p\left(X_{i}\right)-e\left(X_{i}\right)}-\tau_{e}\right]=0, \text { and } \\
& E\left[p\left(X_{i}\right) \frac{T_{i} \cdot Y_{i}}{p\left(X_{i}\right)}-p\left(X_{i}\right) \frac{\left(1-D_{i}\right) \cdot Y_{i}}{1-p\left(X_{i}\right)-e\left(X_{i}\right)}-\tau_{A T T}\right]=0,
\end{aligned}
$$

where $p\left(X_{i}\right)=E\left[T_{i} \mid X_{i}\right]$ is the probability of being in the treatment group and $e\left(X_{i}\right)=E\left[\left(1-T_{i}\right) \cdot D_{i} \mid X_{i}\right]$ is the probability of being in the within-community comparison group.

Given the estimators $\hat{p}\left(X_{i}\right)$ and $\hat{e}\left(X_{i}\right)$, which can be calculated using a multinomial probabilistic model, $\tau_{p}, \tau_{e}$ and $\tau_{A T T}$ are estimated by setting the sample moments equal to zero, leading to the estimators:

$$
\begin{aligned}
& \hat{\tau}_{p}=\left[\sum_{i} T_{i} \cdot Y_{i} / \sum_{i} T_{i}\right]-\left[\sum_{i}\left(1-T_{i}\right) \cdot D_{i} \cdot Y_{i} \frac{\hat{p}\left(X_{i}\right)}{\hat{e}\left(X_{i}\right)} / \sum_{i}\left(1-T_{i}\right) \cdot D_{i} \frac{\hat{p}\left(X_{i}\right)}{\hat{e}\left(X_{i}\right)}\right], \\
& \hat{\tau}_{e}=\left[\sum_{i}\left(1-T_{i}\right) \cdot D_{i} \cdot Y_{i} \frac{\hat{p}\left(X_{i}\right)}{\hat{e}\left(X_{i}\right)} / \sum_{i}\left(1-T_{i}\right) \cdot D_{i} \frac{\hat{p}\left(X_{i}\right)}{\hat{e}\left(X_{i}\right)}\right] \\
& -\left[\sum_{i}\left(1-D_{i}\right) \cdot Y_{i} \frac{\hat{p}\left(X_{i}\right)}{1-\hat{p}\left(X_{i}\right)-\hat{e}\left(X_{i}\right)} /\left(1-D_{i}\right) \frac{\hat{p}\left(X_{i}\right)}{1-\hat{p}\left(X_{i}\right)-\hat{e}\left(X_{i}\right)}\right] \text {, and } \\
& \hat{\tau}=\left[\sum_{i} T_{i} \cdot Y_{i} / \sum_{i} T_{i}\right]-\left[\sum_{i}\left(1-D_{i}\right) \cdot Y_{i} \frac{\hat{p}\left(X_{i}\right)}{1-\hat{p}\left(X_{i}\right)-\hat{e}\left(X_{i}\right)} /\left(1-D_{i}\right) \frac{\hat{p}\left(X_{i}\right)}{1-\hat{p}\left(X_{i}\right)-\hat{e}\left(X_{i}\right)}\right] .
\end{aligned}
$$

As Robins and Rotnizky (1995) point out, if either the model of conditional means (4.13) or the model based on the propensity score (4.15)-(4.17) are correctly specified, the resulting estimator will be consistent. For this reason, Hirano and Imbens (2001) propose a flexible approach combining both models. Hirano and Imbens's estimator is based on weighted least square estimation of equation (4.13), where the control variables on the right-hand side are a 
subset of $X_{i}{ }^{20}$ Based on the estimators (4.18)-(4.20), the estimated weight, applied in these regressions, is given by:

$\hat{\omega}\left(T_{i}, D_{i}, Z_{i}\right)=T_{i}+\left(1-T_{i}\right) \cdot D_{i} \frac{\hat{p}\left(Z_{i}\right)}{\hat{e}\left(Z_{i}\right)}+\left(1-D_{i}\right) \frac{\hat{p}\left(Z_{i}\right)}{1-\hat{p}\left(Z_{i}\right)-\hat{e}\left(Z_{i}\right)}$,

where $Z_{i}$ is a subset of $X_{i}$ that balances both propensities scores.

\subsubsection{Assessing Income Effect and Behavioural-Change Effects}

Besides looking at the externality effect, this paper also proposes a methodology to disentangle the effects of increasing income and the changes induced by behavioural change. Essentially, we propose to decompose each of the APT, AET and ATT parameters into income effect, substitution effect and unexplained effect, using a methodology analogous to those presented by Juhn, Murphy and Pierce (1993), DiNardo, Fortin and Lemieux (1996), and Firpo, Fortin and Lemieux (2007). The income effect represents the change in the outcome, $Y_{i}$, predicted by the income expansion path when the household income increases. The substitution effect represents the effect of changes in the income expansion path on the outcome. That is, given the same level of income, this component assesses the effect of change in the income elasticity promoted by the programme. The unexplained component represents the effect of the programme that is related to neither the income level nor the income elasticity. This component measures an autonomous change in the outcome caused by the programme. Then the sum of the two latter components represents the behavioural-change effect-that is, the component that is not explained by the income increase.

In order to simplify, let $Y_{i}\left(D_{i}=1, T_{i}=1\right)=Y_{i, 1,1}, Y_{i}\left(D_{i}=1, T_{i}=0\right)=Y_{i, 1,0}$, and $Y_{i}\left(D_{i}=0, T_{i}=0\right)=Y_{i, 0,0}$. Then, consider the outcome $Y_{i, D, T}$ as a function of the income level of household $i, W_{i, D, T}$, as follows:

$Y_{i, D, T}=g_{D, T}\left(W_{i, D, T}\right)+u_{i, D, T}$,

where $g_{D, T}(.,$.$) is a nonparametric function and u_{i, D, T}$ represents the unobservable component. As in Juhn, Murphy and Pierce, it is useful to think of $u_{i, D, T}$ as two components: the percentile of household $i$ in the distribution of errors, $\theta_{i}$, and the distribution function of the errors, $F_{D, T}($.$) .$ Then we have $u_{i, D, T}=F_{D, T}^{-1}\left(\theta_{i}\right)$. 
Define $\bar{g}(.,$.$) as a counterfactual function and \bar{F}($.$) as the counterfactual cumulative$ distribution. Then we can rewrite equation (4.22) as:

$$
Y_{i, D, T}=Y_{i, D, T}^{W}+Y_{i, D, T}^{g}+Y_{i, D, T}^{u}
$$

where

$$
\begin{aligned}
Y_{i, D, T}^{W} & =\bar{g}\left(W_{i, D, T}\right)+\bar{F}^{-1}\left(\theta_{i}\right), \\
Y_{i, D, T}^{g} & =\left[g_{D, T}\left(W_{i, D, T}\right)+\bar{F}^{-1}\left(\theta_{i}\right)\right]-\left[\bar{g}\left(W_{i, D, T}\right)+\bar{F}^{-1}\left(\theta_{i}\right)\right] \\
& =g_{D, T}\left(W_{i, D, T}\right)-\bar{g}\left(W_{i, D, T}\right) \\
Y_{i, D, T}^{u} & =\left[g_{D, T}\left(W_{i, D, T}\right)+F_{D, T}^{-1}\left(\theta_{i}\right)\right]-\left[g_{D, T}\left(W_{i, D, T}\right)+\bar{F}^{-1}\left(\theta_{i}\right)\right] \\
& =F_{D, T}^{-1}\left(\theta_{i}\right)-\bar{F}^{-1}\left(\theta_{i}\right) .
\end{aligned}
$$

Note that the functions $\bar{g}(.,$.$) and \bar{F}($.$) are the same for both the treatment and$ comparison groups. Then $Y_{i, D, T}^{W}$ have the same distribution in all groups if and only if $W_{i, D, T}$ have the same distribution. Thus the difference between household $i$ and its counterfactual in terms of $Y_{i, D, T}^{W}$ results only from income variation. The outcome $Y_{i, D, T}^{g}$, on the other hand, maintains the function $\bar{F}\left(\right.$.) constant but lets the function $g_{D, T}(.,$.$) be distinct across groups. Then the$ difference between household $i$ and its counterfactual results from both income variation and change in function $g_{D, T}(.,$.$) . Note, however, that if \bar{g}(.,)=.g_{0,0}(.,$.$) , then$ $Y_{i, 1,1}^{g}-Y_{i, 0,0}^{g}=g_{1,1}\left(W_{i, 1,1}\right)-g_{0,0}\left(W_{i, 1,1}\right)$. Thus the only thing that changes is the income expansion path, $g_{D, T}(.,$.$) . Finally, the distribution of Y_{i, D, T}^{u}$ only changes with respect to the error function, $F_{D, T}^{-1}($.$) .$

From (4.23), we can rewrite the ATT parameter (4.12) as follows:

$$
\begin{aligned}
\tau_{A T T} & =E\left[\left(Y_{i, 1,1}^{W}-Y_{i, 0,0}^{W}\right)+\left(Y_{i, 1,1}^{g}-Y_{i, 0,0}^{g}\right)+\left(Y_{i, 1,1}^{u}-Y_{i, 0,0}^{u}\right) \mid T_{i}=1\right] \\
& =\tau_{A T T}^{W}+\tau_{A T T}^{g}+\tau_{A T T}^{u},
\end{aligned}
$$

where

$$
\begin{aligned}
\tau_{A T T}^{W} & =E\left[\left(Y_{i, 1,1}^{W}-Y_{i, 0,0}^{W}\right) T_{i}=1\right] \\
& =\left[\bar{g}\left(W_{i, 1,1}\right)+\bar{F}^{-1}\left(\theta_{i}\right)\right]-\left[\bar{g}\left(W_{i, 0,0}\right)+\bar{F}^{-1}\left(\theta_{i}\right)\right] \\
& =\bar{g}\left(W_{i, 1,1}\right)-\bar{g}\left(W_{i, 0,0}\right)
\end{aligned}
$$


is the total income effect of the programme on the treated,

$$
\begin{aligned}
\tau_{A T T}^{g} & =E\left[\left(Y_{i, 1,1}^{g}-Y_{i, 0,0}^{g}\right) T_{i}=1\right] \\
& =\left[g_{1,1}\left(W_{i, 1,1}\right)-\bar{g}\left(W_{i, 1,1}\right)\right]-\left[g_{0,0}\left(W_{i, 0,0}\right)-\bar{g}\left(W_{i, 0,0}\right)\right] \\
& =\left[g_{1,1}\left(W_{i, 1,1}\right)-g_{0,0}\left(W_{i, 0,0}\right)\right]-\tau_{A T T}^{W}
\end{aligned}
$$

is the total substitution effect of the programme on the treated, and

$$
\begin{aligned}
\tau_{A T T}^{u} & =E\left[\left(Y_{i, 1,1}^{u}-Y_{i, 0,0}^{u}\right) T_{i}=1\right] \\
& =\left[F_{1,1}^{-1}\left(\theta_{i}\right)-\bar{F}^{-1}\left(\theta_{i}\right)\right]-\left[F_{0,0}^{-1}\left(\theta_{i}\right)-\bar{F}^{-1}\left(\theta_{i}\right)\right] \\
& =F_{1,1}^{-1}\left(\theta_{i}\right)-F_{0,0}^{-1}\left(\theta_{i}\right)
\end{aligned}
$$

is the total unexplained effect of the programme on the treated.

Likewise, the APT and AET parameters can be written respectively as follows:

$$
\begin{aligned}
\tau_{p} & =E\left[\left(Y_{i, 1,1}^{W}-Y_{i, 1,0}^{W}\right)+\left(Y_{i, 1,1}^{g}-Y_{i, 1,0}^{g}\right)+\left(Y_{i, 1,1}^{u}-Y_{i, 1,0}^{u}\right) \mid T_{i}=1\right], \text { and } \\
& =\tau_{p}^{W}+\tau_{p}^{g}+\tau_{p}^{u} \\
\tau_{e} & =E\left[\left(Y_{i, 1,0}^{W}-Y_{i, 0,0}^{W}\right)+\left(Y_{i, 1,0}^{g}-Y_{i, 0,0}^{g}\right)+\left(Y_{i, 1,0}^{u}-Y_{i, 0,0}^{u}\right) \mid T_{i}=1\right] \\
& =\tau_{e}^{W}+\tau_{e}^{g}+\tau_{e}^{u},
\end{aligned}
$$

where $\tau_{p}^{W}, \tau_{p}^{g}$ and $\tau_{p}^{u}$ are respectively the income, substitution and unexplained effects of participation in the programme on the treated; and $\tau_{e}^{W}, \tau_{e}^{g}$ and $\tau_{e}^{u}$ are respectively the income, substitution and unexplained effects of externalities of the programme on the treated.

In order to estimate all these parameters, the first step is to obtain an estimate for the function $g_{1,1}$, as well as for its counterfactuals, $g_{1,0}$ and $g_{0,0}$. Note that when we are interested in decomposing the effect on the treated, $g_{0,0}$ does not represent the income expansion path of the between-community comparison group. It actually represents a counterfactual function for the treatment group if the programme were not implemented. Likewise, $g_{1,0}$ represents a counterfactual function for the treatment group if the programme were implemented but the households were not intended to be treated. 
It is worth mentioning that this decomposition approach is quite sensitive to the choice of $\bar{g}(.,$.$) . For instance, if one chooses \bar{g}(.,)=.g_{0,0}(.,$.$) to decompose the ATT parameter, \tau_{A T T}$, it will be implicitly assumed that the income effect comes earlier than the substitution effect. Then the income effect would be measured given the ex-ante behaviour, while the substitution effect would be measured given that the transfer was already made. With $\bar{g}(.,)=.g_{1,1}(.,),. \tau_{A T T}^{g}$ would represent the substitution effect before the transfer. To avoid this arbitrary assumption on what comes first, we could define different $\bar{g}(.,$.$) for each component so that it represents the$ marginal effect of the component, given the others unchanged..$^{21}$ In this case, however, the equalities (4.24), (4.25) and (4.26) would not hold any longer. Another way to avoid being arbitrary and also to make these equalities hold is to define $\bar{g}(.,$.$) as an average function, say$ $g_{a}(.,$.$) , as in the Shapley decomposition of income distribution (Kakwani, 2000).$

Under assumptions (4.8) and (4.9), along with the balancing property condition, $g_{D, T}(.,$. and $F_{D, T}($.$) can be consistently estimated by weighted Kernel regressions for each group$ separately, where the weight is given by (4.21). The average functions, $g_{a}(.,$.$) and F_{a}($.$) , are also$ estimated by weighted Kernel regressions, but without distinguishing the groups.

The second step is to estimate $Y_{i, D, T}^{W}$, which is the predicted outcome under $\bar{g}(.,$.$) , given$ the observed $W_{i, D, T}$. Then we estimate the ATT, APT and AET effects, as previously described, on the outcome $Y_{i, D, T}^{W}$ to get estimates for $\tau_{A T T}^{W}, \tau_{p}^{W}$ and $\tau_{e}^{W}$, respectively. In order to obtain the estimates for $\tau_{A T T}^{g}, \tau_{p}^{g}$ and $\tau_{e}^{g}$, we first calculate the estimated value of $Y_{i, D, T}^{g}$, which is the difference between the predicted outcomes under $g_{D, T}(.,$.$) and \bar{g}(.,$.$) . Then we estimate the$ respective effect on $Y_{i, D, T}^{g}$ and subtract the estimated income effect from this. Finally, to obtain the estimates for $\tau_{A T T}^{u}, \tau_{p}^{u}$ and $\tau_{e}^{u}$, we subtract the respective estimated income and substitution effects from the estimated ATT.

Since all components are estimated using predicted variables, estimation of the standard errors is not straightforward. It requires a correction as suggested by Schafer and Schenker (1997). Since standard errors for estimates based on propensity score are likewise not straightforward, we opt to calculate all the standard errors using a nonparametric bootstrap, with samples taken independently within each group. It is worth mentioning that once a new sample is drawn, all the steps in the decomposition are repeated, including the Kernel regressions. The only step that is not repeated after resampling is the estimation of the propensity score. 


\subsection{ESTIMATING THE MULTINOMIAL PROPENSITY SCORE}

As already mentioned, since there are two distinct comparison groups, we should estimate a multinomial propensity score that balances the covariates between the treatment and comparison groups. Such an assumption can actually be tested, checking whether the differences in observable characteristics between groups are significant after the propensity score weighting. Once the differences are not significant, it does not matter which link function we use.

In this paper, the propensity score of "multiple" treatment is obtained using a multinomial logistic model as suggested by Lechner (2001), which yields the estimated probability of being in each group. Table 3 presents the estimated coefficients of this model. The covariates, as well as their interactions, are chosen with the aim of satisfying the balancing property for a larger set of pre-treatment variables. This set, obtained from the Ficha Hogar, includes all components of the ICV (the official targeting index) and other variables not considered in the calculation of that index, such as department and area (urban/rural) of residence, possession of identity card by some household members, number of years living in the same neighbourhood, number of household members, sex of household head, and per capita income.

TABLE 3

\section{Estimated Coefficient of Multinomial Propensity Score}

\begin{tabular}{|c|c|c|c|c|}
\hline & \multicolumn{2}{|c|}{$\begin{array}{l}\text { Within-community } \\
\text { comparison group }\end{array}$} & \multicolumn{2}{|c|}{$\begin{array}{l}\text { Between-community } \\
\text { comparison group }\end{array}$} \\
\hline & coef. & std. err. & coef. & std. err. \\
\hline Department of San Pedro & -2.4361 & $0.9267^{* * *}$ & 0.2278 & 0.7516 \\
\hline Rural area & -0.3385 & 0.3310 & -0.0795 & 0.3555 \\
\hline Possession of ID & -0.1366 & 0.2826 & -0.7138 & $0.2391^{* \star *}$ \\
\hline Years in the neighbourhood & 0.0136 & 0.0086 & 0.0245 & $0.0078^{* * *}$ \\
\hline Number of members & -0.4646 & 0.2996 & -0.4168 & $0.2534^{*}$ \\
\hline Squared number of members & 0.0229 & 0.0158 & 0.0273 & $0.0130^{* *}$ \\
\hline Female household head & -0.2980 & 0.2596 & -0.1366 & 0.2309 \\
\hline Per capita income & 0.0000 & 0.0000 & 0.0000 & 0.0000 \\
\hline Squared per capita income & 0.0000 & 0.0000 & 0.0000 & 0.0000 \\
\hline ICV $(\mathrm{c})$ - number of children & -0.1892 & 0.5135 & 0.0687 & 0.4600 \\
\hline $\mathrm{ICV}(\mathrm{h})$ - health condition & 0.7695 & $0.2769^{* * *}$ & 0.0399 & 0.2259 \\
\hline ICV $(e)$ - education & 0.1724 & $0.0556^{* * *}$ & -0.0869 & 0.0555 \\
\hline $\mathrm{ICV}(\mathrm{w})$ - employment & -0.5305 & 0.7653 & -1.1150 & 0.7340 \\
\hline ICV $(\mathrm{h})$ - housing condition & 0.0453 & 0.0529 & -0.2482 & $0.0537^{* * *}$ \\
\hline ICV(s) - public services & 0.4953 & $0.1427^{* \star *}$ & 0.0132 & 0.1266 \\
\hline ICV(a) - asset ownership & 0.1701 & $0.0483^{* \star *}$ & 0.0578 & 0.0511 \\
\hline $\mathrm{HH}$ members $\mathrm{x} I \mathrm{ICV}(\mathrm{c})$ & 0.0190 & 0.0680 & -0.0285 & 0.0580 \\
\hline Department x ICV(h) & 0.4290 & 0.2718 & 0.1309 & 0.2304 \\
\hline $\operatorname{ICV}(w) \times \operatorname{ICV}(h)$ & 0.1163 & 0.2037 & 0.3014 & 0.1983 \\
\hline $\operatorname{ICV}(\mathrm{h}) \times \operatorname{ICV}(\mathrm{s})$ & -0.1096 & $0.0417^{* * *}$ & -0.0097 & 0.0380 \\
\hline $\operatorname{ICV}(\mathrm{s}) \times \operatorname{ICV}(\mathrm{h})$ & 0.0099 & 0.0063 & 0.0226 & $0.0061^{\star \star \star *}$ \\
\hline Intercept & -4.3709 & $1.8106^{* *}$ & 1.3913 & 1.5158 \\
\hline Number of observations & 1,093 & & g likelihood & $-778.0 s$ \\
\hline
\end{tabular}


On the basis of the estimated propensity score, we restrict the "weighted" or "matched" sample to those households within a common support. This common support is defined by the probability of being in each of the three groups between 1 per cent and 98 per cent.

TABLE 4

\section{Estimated Coefficient of Multinomial Propensity Score}

\begin{tabular}{|c|c|c|c|c|c|c|c|}
\hline \multirow[b]{2}{*}{ With PS weighting } & \multicolumn{2}{|c|}{ Treatment group } & \multicolumn{2}{|c|}{$\begin{array}{l}\text { Within-community } \\
\text { comparison group }\end{array}$} & \multicolumn{3}{|c|}{$\begin{array}{l}\text { Between-community } \\
\text { comparison group }\end{array}$} \\
\hline & mean & std. err. & mean & std. err. & mean & std. err. & \\
\hline Department of San Pedro & 0.4444 & 0.0280 & 0.4049 & 0.0237 & 0.6727 & $0.0252^{\star \star \star}$ & "' \\
\hline Rural area & 0.8801 & 0.0183 & 0.5409 & $0.0241^{\star \star \star}$ & 0.8062 & $0.0213^{\star \star \star}$ & "' \\
\hline Possession of ID & 0.8662 & 0.0192 & 0.8591 & 0.0168 & 0.7525 & $0.0232^{* \star \star}$ & "' \\
\hline Years in the neighbourhood & 11.154 & 0.6216 & 11.878 & 0.6459 & 14.209 & $0.8075^{\star \star \star}$ & $"$ \\
\hline Number of members & 6.1206 & 0.1338 & 5.1761 & $0.1010^{* \star \star}$ & 6.2555 & 0.1477 & "' \\
\hline Female household head & 0.2539 & 0.0245 & 0.1891 & $0.0189^{* *}$ & 0.2036 & 0.0216 & \\
\hline Per capita income & 36357.5 & 2608.1 & 125724.2 & $7962.3^{\star \star \star}$ & 78041.0 & $6153.1^{\star \star \star}$ & "' \\
\hline ICV - number of children & 1.6380 & 0.0387 & 1.9190 & $0.0247^{\star \star \star}$ & 1.6476 & 0.0390 & "' \\
\hline ICV - health condition & 3.1180 & 0.0459 & 3.3759 & $0.0432^{\star \star \star}$ & 3.2850 & $0.0452^{* * \star}$ & \\
\hline ICV - education & 3.7306 & 0.0974 & 5.7939 & $0.1399^{\star \star \star}$ & 3.6756 & 0.1194 & "' \\
\hline ICV - employment & 0.3119 & 0.0287 & 0.7791 & $0.0493^{\star \star \star}$ & 0.3860 & 0.0352 & "' \\
\hline ICV - housing condition & 8.7593 & 0.1975 & 15.0191 & $0.2758^{\star \star \star}$ & 9.4192 & $0.2815^{\star}$ & "' \\
\hline ICV - public services & 4.6874 & 0.1350 & 9.3792 & $0.2275^{\star \star \star}$ & 6.5461 & $0.2010^{\star \star \star}$ & "' \\
\hline ICV - asset ownership & 1.0051 & 0.1015 & 3.1119 & $0.1205^{\star \star \star}$ & 1.6271 & $0.1179^{\star \star \star}$ & "' \\
\hline ICV - total & 23.250 & 0.3773 & 39.378 & $0.6335^{\star \star \star}$ & 26.587 & $0.6095^{\star \star \star}$ & "' \\
\hline Number of observations & 331 & & 521 & & 322 & & \\
\hline Without PS weighting & mean & std. err. & mean & std. err. & mean & std. err. & \\
\hline Department of San Pedro & 0.4218 & 0.0287 & 0.5293 & $0.0252^{\star \star \star}$ & 0.4841 & 0.0284 & \\
\hline Rural area & 0.8755 & 0.0192 & 0.9093 & 0.0145 & 0.9022 & 0.0169 & \\
\hline Possession of ID & 0.8781 & 0.0190 & 0.8781 & 0.0165 & 0.8544 & 0.0201 & \\
\hline Years in the neighbourhood & 11.387 & 0.6426 & 11.649 & 0.5626 & 12.379 & 0.7270 & \\
\hline Number of members & 6.0608 & 0.1354 & 5.9958 & 0.1230 & 6.1228 & 0.1382 & \\
\hline Female household head & 0.2535 & 0.0253 & 0.2177 & 0.0208 & 0.2187 & 0.0235 & \\
\hline Per capita income & 36858.9 & 2718.5 & 39219.0 & 2482.6 & 35390.9 & 2381.8 & \\
\hline ICV - number of children & 1.6747 & 0.0385 & 1.7387 & 0.0304 & 1.6512 & 0.0401 & ' \\
\hline ICV - health condition & 3.1971 & 0.0436 & 3.2735 & 0.0342 & 3.1018 & 0.0403 & "' \\
\hline ICV - education & 3.7807 & 0.1019 & 3.6950 & 0.0956 & 3.5589 & $0.0863^{\star}$ & \\
\hline ICV - employment & 0.3186 & 0.0300 & 0.2587 & 0.0317 & 0.2781 & 0.0305 & \\
\hline ICV - housing condition & 8.9901 & 0.2002 & 8.7195 & 0.1658 & 9.1095 & 0.2333 & \\
\hline ICV - public services & 4.8544 & 0.1365 & 4.9600 & 0.1288 & 4.6809 & 0.1433 & \\
\hline ICV - asset ownership & 1.0702 & 0.1070 & 0.9480 & 0.0885 & 1.0772 & 0.1017 & \\
\hline ICV - total & 23.886 & 0.3695 & 23.593 & 0.3089 & 23.458 & 0.3854 & \\
\hline Number of observations & 297 & & 394 & & 310 & & \\
\hline
\end{tabular}

Note: ${ }^{* * *}$ signif. different from treatment at $1 \%,{ }^{* *}$ signif. different from treatment at $5 \%,{ }^{*}$ signif. different from treatment at $10 \%$. "' signif. different from W-C comparison at 1\%, " signif. different from W-C comparison at $5 \%$, ' signif. different from W-C comparison at $10 \%$.

Table 4 presents the mean of covariates for each group before and after the propensity score weighting. For all variables, there is at least one group that is significantly different from another. After the propensity score weighting and restriction to the common support, however, the differences almost disappear in terms of mean. The only significant differences that remain 
are in the department of residence and in the number of children, health and education components of the ICV. For this reason, these variables are also included in the regression adjustment - that is on the right-hand side of equation (4.13).

Figure 1 shows how the propensity score weighting changes the distribution of the ICV for the comparison groups. In the panel on the left with the unweighted distributions, the comparison groups' distributions have a longer right tail than the treatment group's: the probability of higher ICV values is greater in the comparison groups, mainly in the withincommunity group. The panel on the right shows how the weighting scheme changes the ICV distribution of the comparison groups so that it resembles the distribution of the treatment group. The weighting scheme thus approximates the groups not only in terms of means, as shown in Table 4, but also in terms of the whole distribution.

FIGURE 1

\section{Kernel Density of the ICV for the Treatment and Comparison Groups}
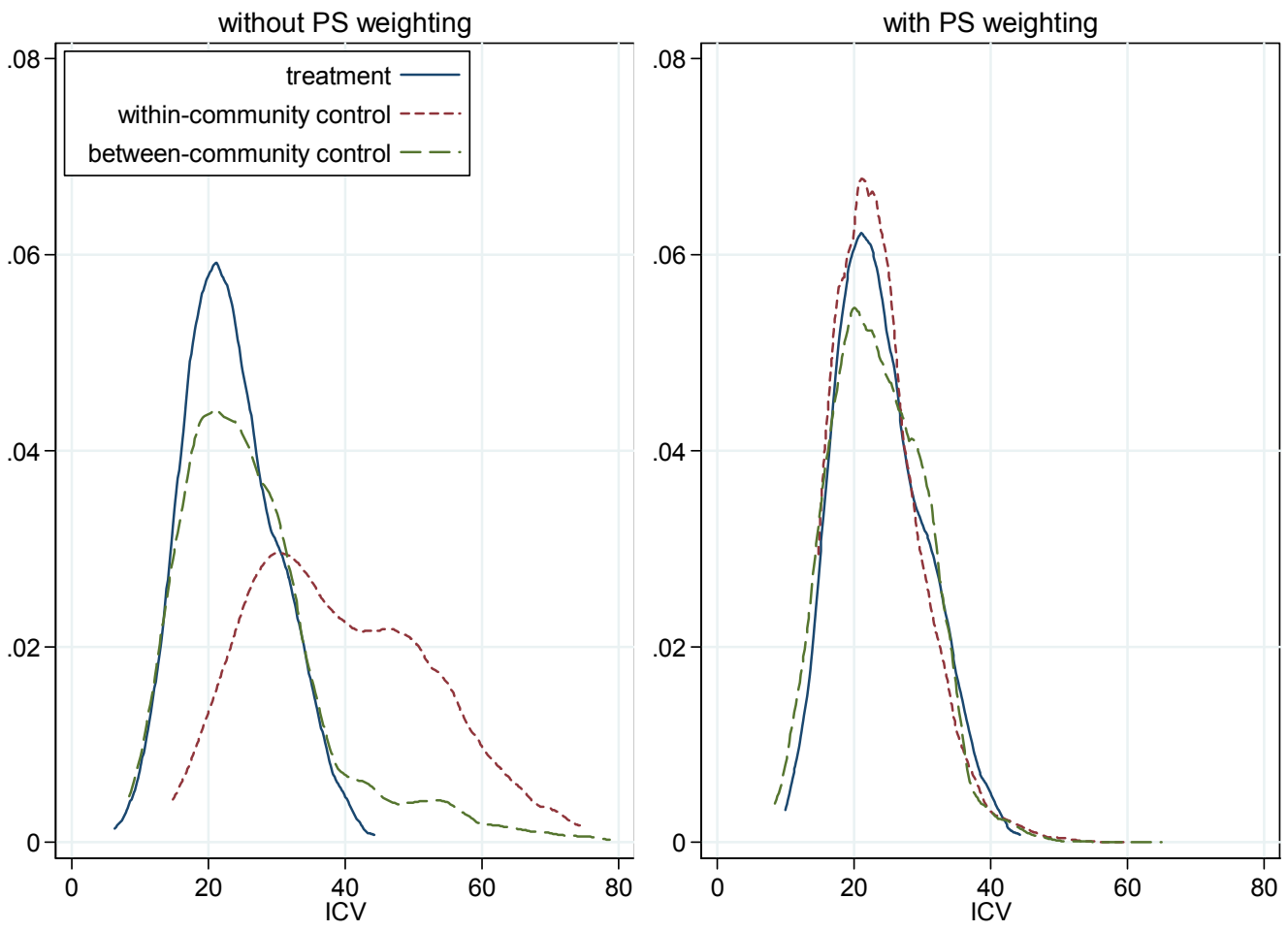

The ICV is actually the main determinant of participation in the Tekoporã programme, and no significant difference between the treated and untreated groups is found after the propensity score weighting. Thus we can assume conditions (4.8) and (4.9) of selection of households based on observables and achieve consistent results. With regard to the adequacy of propensity score methods to evaluate CCT programmes, Handa and Diaz (2006) and Handa and Maluccio (2010) show that these methods are capable of reproducing the experimental results for the cases of PROGRESA and RPS, respectively, even in a non-experimental setting. ${ }^{22}$ 


\section{EMPIRICAL RESULTS}

This section is divided into three parts. The first presents descriptive statistics for the treatment group, the within-community comparison group and the between-community comparison group. The second encompasses the estimates of Tekoporã's average effect (ATT), participation effect (APT), and externality effect (AET) on consumption. The third shows the estimated decompositions of these three effects into income, substitution and unexplained effects.

\subsection{DESCRIPTIVE STATISTICS}

The decompositions proposed in this paper are applied to investigate the effect of the Tekoporã programme on household consumption and expenditures. In particular, we estimate the effect on total expenditures on consumption, expenditures on food, and the saving rate. Expenditures, which include self-production and other non-monetary expenditures, are measured by logarithm of the per capita amount. The saving rate is defined as the difference between the logarithms of monthly net income and expenditures on consumption (Deaton, 1997) - that is, the proportion of income in cash and in kind, discounting taxes and transfers to others, that a household receives more (or less) than its expenditures on consumption. We also estimate the effect on consumption basket composition, assessed by the share of consumption spent on distinct items - for example, the shares of expenditures on food, education, health, child clothing, adult clothing and housing. ${ }^{23}$

Table 5 presents the descriptive statistics for those outcome variables post-treatment. ${ }^{24}$ Note that the total consumption level, as well as food consumption, is about 9 per cent higher in the comparison groups. The saving rate, on the other hand, is much higher in the treatment group than in the other groups. Current income in the treated households is almost 3 per cent higher than their consumption, whereas the comparison households spend on average more than they earn. Moreover, the mean saving rate in the within-community comparison group is significantly higher than in the other comparison group, which cannot be affected by the programme in any way.

TABLE 5

Descriptive Analysis of Outcomes

\begin{tabular}{|c|c|c|c|c|c|c|c|}
\hline & \multicolumn{2}{|c|}{ Treatment group } & \multicolumn{2}{|c|}{$\begin{array}{l}\text { Within-community } \\
\text { comparison group }\end{array}$} & \multicolumn{3}{|c|}{$\begin{array}{l}\text { Between-community } \\
\text { comparison }\end{array}$} \\
\hline & mean & std. err. & mean & std. err. & mean & std. err. & \\
\hline log per capita consumption & 11.6545 & 0.03401 & 11.7385 & $0.02719^{*}$ & 11.7628 & $0.03352^{* *}$ & \\
\hline $\log p c$ food consumption & 11.4236 & 0.03867 & 11.5231 & $0.02656^{* \star}$ & 11.5141 & $0.03279^{*}$ & \\
\hline saving rate & 0.02970 & 0.03532 & -0.13635 & $0.03775^{\star \star \star}$ & -0.28521 & $0.04339^{* \star \star}$ & "' \\
\hline share of food expenditures & 0.81731 & 0.00922 & 0.82262 & 0.00789 & 0.79784 & 0.00850 & $"$ \\
\hline share of education exp. & 0.01032 & 0.00260 & 0.00701 & 0.00138 & 0.01072 & 0.00232 & \\
\hline share of health exp. & 0.03643 & 0.00463 & 0.04203 & 0.00402 & 0.03703 & 0.00481 & \\
\hline share of child clothing exp. & 0.02876 & 0.00290 & 0.01484 & $0.00173^{* \star *}$ & 0.01619 & $0.00177^{* \star *}$ & \\
\hline share of adult clothing exp. & 0.00996 & 0.00207 & 0.00584 & $0.00106^{*}$ & 0.01286 & 0.00192 & "' \\
\hline share of housing exp. & 0.05100 & 0.00352 & 0.04536 & 0.00256 & 0.05877 & 0.00351 & "' \\
\hline Number of observations & 297 & & 394 & & 310 & & \\
\hline
\end{tabular}

Note: ${ }^{* * *}$ signif. different from treatment at $1 \%,{ }^{* *}$ signif. different from treatment at $5 \%,{ }^{*}$ signif. different from treatment at 10\%. "' signif. different from W-C comparison at 1\%, " signif. different from W-C comparison at 5\%, ' signif. different from $\mathrm{W}-\mathrm{C}$ comparison at $10 \%$. 
Although mean food consumption is greater in the comparison group, its mean food share does not differ significantly from the treatment group's. Among households in this sample, about 80 per cent of spending is on food. The mean food share in the within-community comparison group, though, is significantly greater than in the between-community group. The shares of adult clothing and housing expenditures in the latter group, on the other hand, are significantly higher than in the former comparison group. On average, among these households about 5 per cent of spending is on housing and 1 per cent on adult clothing. The mean share of child clothing is also around 1 per cent in the comparison groups. In the treatment group, however, this mean share is almost 3 per cent. Finally, households in the three groups spend about 1 per cent on education and 4 per cent on health.

\subsection{PARTICIPATION, EXTERNALITY AND TOTAL EFFECTS OF TEKOPORÃ}

Table 6 presents the estimates for the average participation effect on the treated (APT), average externality effect on the treated (AET), and average treatment effect on the treated (ATT), which is the sum of the former effects. If the programme had no externality effect, it would increase the level of consumption by 21 per cent, food consumption by 15 per cent, and by 0.7 percentage points the share of adult clothing among treated households. But the externality effects of the programme on these outcomes are all negative. Hence the externality cancels out the participation effect, making the total effect of the programme on these outcomes null or even negative, as on food consumption. Likewise, the programme would reduce the share of food consumption by 4 percentage points in the absence of externality. Nonetheless, given the small externality effect on this outcome, the total effect of the programme on the food share of treated households is insignificant.

TABLE 6

Estimated APT, AET and ATT on Household Consumption

\begin{tabular}{|c|c|c|c|}
\hline & APT & AET & ATT \\
\hline \multirow[t]{2}{*}{ log per capita consumption } & $0.21106^{\star \star \star}$ & $-0.29765^{\star \star \star}$ & -0.08659 \\
\hline & $(0.07504)$ & $(0.08055)$ & $(0.05464)$ \\
\hline \multirow[t]{2}{*}{ log pc food consumption } & $0.14844^{\star \star}$ & $-0.26999^{\star \star \star}$ & $-0.12155^{\star \star}$ \\
\hline & $(0.07506)$ & $(0.07896)$ & $(0.06081)$ \\
\hline \multirow[t]{2}{*}{ saving rate } & $0.15757^{\star \star}$ & $0.14956^{*}$ & $0.30713^{* * *}$ \\
\hline & $(0.07402)$ & $(0.08785)$ & $(0.07347)$ \\
\hline \multirow[t]{2}{*}{ share of food expenditures } & $-0.03944^{\star \star}$ & 0.02197 & -0.01747 \\
\hline & $(0.01549)$ & $(0.01612)$ & $(0.01409)$ \\
\hline \multirow[t]{2}{*}{ share of education exp. } & $0.00592^{*}$ & -0.00282 & 0.00310 \\
\hline & $(0.00341)$ & $(0.00354)$ & $(0.00404)$ \\
\hline \multirow[t]{2}{*}{ share of health exp. } & 0.00405 & 0.00788 & $0.01193^{*}$ \\
\hline & $(0.00765)$ & $(0.00686)$ & $(0.00645)$ \\
\hline \multirow[t]{2}{*}{ share of child clothing exp. } & $0.01504^{\star \star \star}$ & 0.00316 & $0.01819^{\star \star \star}$ \\
\hline & $(0.00403)$ & $(0.00327)$ & $(0.00332)$ \\
\hline \multirow[t]{2}{*}{ share of adult clothing exp. } & $0.00678^{\star \star \star}$ & $-0.01005^{\star \star \star}$ & -0.00326 \\
\hline & $(0.00222)$ & $(0.00284)$ & $(0.00345)$ \\
\hline \multirow[t]{2}{*}{ share of housing exp. } & 0.00891 & -0.00987 & -0.00096 \\
\hline & $(0.00662)$ & $(0.00716)$ & $(0.00571)$ \\
\hline
\end{tabular}

Note: ${ }^{* * *}$ significant at $1 \%,{ }^{* *}$ significant at $5 \%,{ }^{*}$ significant at $10 \%$.

Standard errors, between parentheses, calculated using 1,000 bootstrap resampling. 
Even though the participation effect on food consumption is positive, the negative participation effect on food share is explained by a higher increase in other types of expenditure, such as on child and adult clothing. Unlike the effect on share of adult clothing, the participation effect on share of child clothing is not offset by the externality effect, which makes the total effect on this outcome about 18 percentage points.

An externality effect that boosts the participation effect is on savings. Each component contributes about 50 per cent to the total impact of the programme on the saving rate, which is at 31 per cent. The positive externality on savings explains why the externality on consumption is negative. The programme encourages an increase in the saving rate even if the household was not being treated but was in a treated community. This externalised behaviour makes households reduce consumption in order to save more of their income.

\subsection{INCOME EFFECT AND BEHAVIOURAL CHANGE EFFECTS OF TEKOPORÃ}

To understand the previous results better, we can also decompose those effects into income effect, substitution effect and unexplained effect. In the tables in this section, the first column shows the estimated marginal income effect (MIE), which is the impact that the programme would have if it only caused an increase in household income. This effect represents the impact of the programme if it were unconditional and did not have other components besides income transfer. The next column presents the income effect (IE) taking into consideration that the income expansion path has also been changing - that is, it gives the contribution of income increase per se to the programme impact. The third column shows the substitution effect (SE), which is the contribution of changes in income elasticity, taking into account that household income has been increasing. The last column presents the unexplained effect (UE), which is the contribution of changes that are not related to either income level or elasticity.

TABLE 7

Estimated Decomposition of the APT on Household Consumption

\begin{tabular}{|c|c|c|c|c|}
\hline & MIE & IE & SE & UE \\
\hline log per capita consumption & $\begin{array}{l}0.13117^{\text {*t* }} \\
(0.0356)\end{array}$ & $\begin{array}{l}0.12365^{* * *} \\
(0.0389)\end{array}$ & $\begin{array}{l}0.06970 \\
(0.0689)\end{array}$ & $\begin{array}{l}0.01771 \\
(0.0292)\end{array}$ \\
\hline log pc food consumption & $\begin{array}{l}0.13635^{\star \star *} \\
(0.0372)\end{array}$ & $\begin{array}{l}0.13207^{* * *} \\
(0.0377)\end{array}$ & $\begin{array}{l}0.00384 \\
(0.0700)\end{array}$ & $\begin{array}{l}0.01254 \\
(0.0300)\end{array}$ \\
\hline saving rate & $\begin{array}{l}0.17906^{*+*} \\
(0.0453)\end{array}$ & $\begin{array}{l}0.15358^{* * *} \\
(0.0383)\end{array}$ & $\begin{array}{l}0.02963 \\
(0.0700)\end{array}$ & $\begin{array}{r}-0.02564 \\
(0.0314)\end{array}$ \\
\hline share of food expenditures & $\begin{array}{l}0.00161 \\
(0.0038)\end{array}$ & $\begin{array}{l}0.00108 \\
(0.0028)\end{array}$ & $\begin{array}{c}-0.03329^{* *} \\
(0.0156)\end{array}$ & $\begin{array}{r}-0.00722 \\
(0.0082)\end{array}$ \\
\hline share of education exp. & $\begin{array}{r}-0.00064 \\
(0.0011)\end{array}$ & $\begin{array}{r}-0.00093 \\
(0.0006)\end{array}$ & $\begin{array}{l}0.00503 \\
(0.0033)\end{array}$ & $\begin{array}{l}0.00181 \\
(0.0015)\end{array}$ \\
\hline share of health exp. & $\begin{array}{r}-0.00244 \\
(0.0023)\end{array}$ & $\begin{array}{r}-0.00038 \\
(0.0011)\end{array}$ & $\begin{array}{l}0.00251 \\
(0.0078)\end{array}$ & $\begin{array}{l}0.00191 \\
(0.0034)\end{array}$ \\
\hline share of child clothing exp. & $\begin{array}{r}-0.00009 \\
(0.0006)\end{array}$ & $\begin{array}{l}0.00010 \\
(0.0007)\end{array}$ & $\begin{array}{l}0.01312^{* \star *} \\
(0.0042)\end{array}$ & $\begin{array}{l}0.00181 \\
(0.0019)\end{array}$ \\
\hline share of adult clothing exp. & $\begin{array}{l}0.00091 \\
(0.0012)\end{array}$ & $\begin{array}{l}0.00021 \\
(0.0008)\end{array}$ & $\begin{array}{l}0.00598^{\star \star *} \\
(0.0022)\end{array}$ & $\begin{array}{l}0.00060 \\
(0.0008)\end{array}$ \\
\hline share of housing exp. & $\begin{array}{l}0.00052 \\
(0.0017)\end{array}$ & $\begin{array}{l}0.00098 \\
(0.0014)\end{array}$ & $\begin{array}{l}0.00644 \\
(0.0069)\end{array}$ & $\begin{array}{l}0.00149 \\
(0.0032)\end{array}$ \\
\hline
\end{tabular}

Note: ${ }^{* * *}$ significant at $1 \%,{ }^{* *}$ significant at $5 \%,{ }^{*}$ significant at $10 \%$.

Standard errors, between parentheses calculated using 1,000 bootstrap resampling.

$\mathrm{MIE}=$ Marginal Income Effect, IE = Income Effect, $\mathrm{SE}=$ Substitution Effect, UE = Unexplained Effect. 
Table 7 presents the estimated decomposition of the average participation effect (APT). Assuming that the programme would have no externality, its effects on consumption and savings would be wholly explained by the income increase. The effects on consumption composition, on the other hand, are entirely explained by changes in the income elasticity. If there were no interaction between households, therefore, an unconditional transfer would cause the same increase in household consumption and savings as the programme did. Unlike the programme, however, this unconditional transfer would cause no significant change in the consumption basket composition.

Table 8 presents the estimated decomposition of the AET. As expected, the externality of the programme is not caused by its transfer, but by the behavioural change that it promotes. According to the method of decomposition, the income effect would be externalised if the transfer had a multiplicative effect on the community. Hence we can state that the cash transfer by itself has no effect on aggregate demand, at least in the case of Tekoporã.

TABLE 8

Estimated Decomposition of the AET on Household Consumption

\begin{tabular}{lcccc}
\hline & MIE & IE & SE & UE \\
\hline log per capita consumption & -0.04896 & -0.04936 & $-0.22560^{* * *}$ & -0.02270 \\
& $(0.0352)$ & $(0.0386)$ & $(0.0768)$ & $(0.0331)$ \\
log pc food consumption & -0.05275 & -0.05292 & $-0.19707^{* * *}$ & -0.02000 \\
& $(0.0366)$ & $(0.0394)$ & $(0.0759)$ & $(0.0334)$ \\
saving rate & -0.07443 & -0.05727 & $0.18515^{* *}$ & 0.02169 \\
& $(0.0563)$ & $(0.0488)$ & $(0.0726)$ & $(0.0323)$ \\
share of food expenditures & -0.00005 & -0.00071 & 0.02101 & 0.00167 \\
& $(0.0028)$ & $(0.0021)$ & $(0.0170)$ & $(0.0096)$ \\
share of education exp. & 0.00040 & 0.00040 & -0.00360 & 0.00038 \\
& $(0.0007)$ & $(0.0005)$ & $(0.0038)$ & $(0.0016)$ \\
share of health exp. & 0.00166 & 0.00077 & 0.00931 & -0.00220 \\
share of child clothing exp. & $(0.0017)$ & $(0.0009)$ & $(0.0072)$ & $(0.0035)$ \\
share of adult clothing exp. & 0.00010 & -0.00004 & 0.00332 & -0.00012 \\
share of housing exp. & $(0.0005)$ & $(0.0004)$ & $(0.0036)$ & $(0.0019)$ \\
& -0.00021 & 0.00002 & $-0.01019^{* * *}$ & 0.00012 \\
& $(0.0008)$ & $(0.0005)$ & $(0.0028)$ & $(0.0011)$ \\
& -0.00046 & -0.00040 & -0.00841 & -0.00106 \\
& $(0.0012)$ & $(0.0011)$ & $(0.0074)$ & $(0.0035)$ \\
\hline
\end{tabular}

Note: ${ }^{* * *}$ significant at $1 \%,{ }^{* *}$ significant at $5 \%,{ }^{*}$ significant at $10 \%$.

Standard errors, between parentheses calculated using 1,000 bootstrap resampling.

$\mathrm{MIE}=$ Marginal Income Effect, IE = Income Effect, $\mathrm{SE}=$ Substitution Effect, UE = Unexplained Effect.

Table 9 shows the estimates for the ATT decomposition, which can be read as the sum of estimates for each outcome and component presented in the previous tables. In terms of consumption and saving, the income component, which is mostly related to the effect of participation, is positive: the cash transfer per se has a direct positive effect on consumption and savings. On the other hand, the programme also has a substitution effect, which is mostly related to externalities. It has an effect on household behaviour that indirectly cancels out the income effect on consumption and boosts the income effect on savings.

As shown earlier, the income component contributes to neither the participation effect nor the externality effect in terms of expenditure share. Thus it is expected that the programme's identified impact on the share of child clothing expenditures is entirely explained by the substitution effect. 
TABLE 9

Estimated Decomposition of the ATT on Household Consumption

\begin{tabular}{|c|c|c|c|c|}
\hline & MIE & IE & SE & UE \\
\hline \multirow[t]{2}{*}{ log per capita consumption } & $0.08221^{\star \star \star}$ & $0.07430^{* * *}$ & $-0.15590^{\star \star \star}$ & -0.00498 \\
\hline & $(0.0279)$ & $(0.0287)$ & $(0.0501)$ & $(0.0215)$ \\
\hline \multirow[t]{2}{*}{$\log$ pc food consumption } & $0.08360^{\star \star \star}$ & $0.07915^{* * *}$ & $-0.19323^{\star \star \star}$ & -0.00747 \\
\hline & $(0.0289)$ & $(0.0292)$ & $(0.0551)$ & $(0.0214)$ \\
\hline \multirow[t]{2}{*}{ saving rate } & $0.10463^{\star *}$ & $0.09631^{* *}$ & $0.21478^{\star \star \star}$ & -0.00395 \\
\hline & $(0.0454)$ & $(0.0405)$ & $(0.0542)$ & $(0.0269)$ \\
\hline \multirow[t]{2}{*}{ share of food expenditures } & 0.00157 & 0.00037 & -0.01229 & -0.00556 \\
\hline & $(0.0028)$ & $(0.0019)$ & $(0.0152)$ & $(0.0066)$ \\
\hline \multirow[t]{2}{*}{ share of education exp. } & -0.00024 & -0.00052 & 0.00143 & 0.00219 \\
\hline & $(0.0006)$ & $(0.0004)$ & $(0.0040)$ & $(0.0015)$ \\
\hline \multirow[t]{2}{*}{ share of health exp. } & -0.00078 & 0.00039 & $0.01183^{\star}$ & -0.00029 \\
\hline & $(0.0014)$ & $(0.0008)$ & $(0.0064)$ & $(0.0018)$ \\
\hline \multirow[t]{2}{*}{ share of child clothing exp. } & 0.00001 & 0.00007 & $0.01644^{\star \star \star}$ & 0.00169 \\
\hline & $(0.0004)$ & $(0.0005)$ & $(0.0035)$ & $(0.0013)$ \\
\hline \multirow[t]{2}{*}{ share of adult clothing exp. } & 0.00070 & 0.00023 & -0.00422 & 0.00072 \\
\hline & $(0.0009)$ & $(0.0007)$ & $(0.0034)$ & $(0.0010)$ \\
\hline \multirow[t]{2}{*}{ share of housing exp. } & 0.00007 & 0.00058 & -0.00198 & 0.00043 \\
\hline & $(0.0012)$ & $(0.0011)$ & $(0.0060)$ & $(0.0019)$ \\
\hline
\end{tabular}

Note: ${ }^{* * *}$ significant at $1 \%,{ }^{* *}$ significant at $5 \%,{ }^{*}$ significant at $10 \%$.

Standard errors, between parentheses calculated using 1,000 bootstrap resampling.

$\mathrm{MIE}=$ Marginal Income Effect, IE = Income Effect, $\mathrm{SE}=$ Substitution Effect, UE = Unexplained Effect.

\section{CONCLUSION}

This paper deals with two relevant issues in discussions of the impacts of CCT programmes. First, we discuss the existence of externality and propose to decompose the average treatment effect on the treated (ATT) into two components: the average participation effect on the treated (APT), which represents the direct impact of the programme; and the average externality effect on the treated (AET), which represents the programme's indirect impact. The expected direction and magnitude of the indirect effect are quite pertinent to the decision on programme coverage. If the externality has an effect contrary to what is intended, then the higher the coverage, the worse the outcomes. Otherwise, a higher coverage would improve the expected outcomes. ${ }^{25}$

Second, we decompose those three parameters into income effect, substitution effect and unexplained effect. We can then understand whether the programme impact is due either to the relaxation of the household budget constraint (like a pure income effect) or to changes in the household behaviour triggered by conditionalities and other components of the programme. As argued by Handa et al. (2009), conditionalities, as well as other components, are a substantial part of the programmes' budgets and are hard to monitor. They should really contribute to the programmes' impact in order to be justified as a component.

After applying the suggested methodology, we find that in addition to its direct effects, the Tekoporã programme also has indirect effects or externalities. Thus if we did not differentiate the comparison group between those living in treated communities and those living in other communities, we would violate the Stable-Unit-Treatment-Value Assumption (SUTVA), which, according to Rubin $(1980,1986)$, is required to estimate causal effects. The comparison group 
would be contaminated by households that have also been affected by the programme. Furthermore, we show that externalities are entirely associated with changes in household behaviour. This suggests that the programme has an indirect effect, not because it has a multiplicative effect on aggregate demand, but because there may be a social interaction component behind this effect.

If there were no externality, the programme would increase household consumption significantly. This effect, however, is offset by households' behavioural response to the programme. Angelucci and Di Giorgi (2006) find different results in terms of consumption for PROGRESA. But they assess externality only for a group of non-eligible households, which somehow are able to profit from the extra income in their community. In the case of Tekoporã, the role of "family guides" is also worth mentioning. They are meant to help households plan their budgets better. In a seasonal, agricultural economy, budget planning means precautionary savings. Thus the "saving message" transmitted by the family guides may have spilled over to other poor households, causing them to reduce consumption.

While the impact on savings is caused partly by the increase in income, the impact on consumption composition is entirely explained by the behavioural change promoted by the programme. In contrast to the finding of Handa et al. (2009), this result suggests that, at least in the case of Tekoporã, the cash transfer plays no role in changing the consumption pattern, but conditionalities and family guides' work do. The programme directly encourages beneficiary households to reduce relative expenditure on food and increase the share of child and adult clothing. Nonetheless, the only effect that remains taking externality into account is on the share of child clothing. Because of its other components beyond cash, therefore, the programme is effective in improve the share of expenditure going to children. 


\section{REFERENCES}

Agüero, J. M., M. R. Carter and I. Woolard (2007). 'The Impact of Unconditional Cash Transfers on Nutrition: The South Africa Child Support Grant', IPC-IG Working Paper 39. Brasilia, International Policy Centre for Inclusive Growth.

Angelucci, M. and G. De Giorgi (2009). 'Indirect Effects of an Aid Program: How Do Cash Transfers Affect Ineligibles' Consumption?' American Economic Review 99 (1), 486-508.

Angelucci, M. et al. (2009). 'Family Networks and School Enrolment: Evidence from a Randomized Social Experiment', Working Paper 14949. National Bureau of Economic Research. Attanasio, O. and V. Lechene (2002). 'Tests of Income Pooling in Household Decisions', Review of Economic Dynamics 5, 720-748.

Attanasio, O. and A. Mesnard (2006). 'The Impact of a Conditional Cash Transfer Programme on Consumption in Colombia', Fiscal Studies 27 (4), 421-442.

Attanasio, O. et al. (2005). The Short-Term Impact of a Conditional Cash Subsidy on Child Health and Nutrition in Colombia. Report Summary: Familias 03. London, Institute of Fiscal Studies.

Barrera-Osorio, F. et al. (2008). 'Conditional Cash Transfers in Education: Design Features, Peer and Sibling Effects: Evidence from a Randomized Experiment in Colombia', Working Paper 13890. National Bureau of Economic Research.

Bobonis, G. J. and F. Finan (2009). 'Neighborhood Peer Effects in Secondary School Enrollment Decisions,' Review of Economics and Statistics 91 (4), 695-716.

Brauw, A. de and J. Hoddinott (2007). 'Must Conditional Cash Transfer Programs Be Conditioned to Be Effective?' Discussion Paper 757. Washington, DC, International Food Policy

Research Institute.

Caldes, N., D. Coady and J. Maluccio (2006). 'The Cost of Poverty Alleviation Transfer Programs: A Comparative Analysis of Three Programs in Latin America', World Development 34 (5), 818-837.

Case, A. and A. Deaton (1998). 'Large Cash Transfers to the Elderly in South Africa', Economic Journal 108 (450), 1330-1361.

Deaton, A. (1997). The Analysis of Household Surveys. A Microeconometric Approach to Development Policy. Baltimore, John Hopkins University Press.

Dehejia, R. H. and S. Wahba (2002). 'Propensity Score-Matching Methods for Nonexperimental Causal Studies', Review of Economics and Statistics 84 (1), 151-161.

Diaz, J. J. and S. Handa (2006). 'An Assessment of Propensity Score Matching as a Nonexperimental Impact Estimator: Evidence from Mexico's PROGRESA Program', Journal of Human Resources 41(2), 319-345.

DiNardo, J., N. M. Fortin and T. Lemieux (1996), 'Labor Market Institutions and the Distribution of Wages, 1973-1992: A Semiparametric Approach', Econometrica 65, 1001-1044.

Doss, C. (1996). 'Testing among Models of Intrahousehold Resource Allocation', World Development 24 (10), 1597-1609.

Duflo, E. (2003). 'Grandmothers and Granddaughters: Old age Pension and Intra-Household Allocation in South Africa', World Bank Economic Review 17 (1), 1-25. 
Edmonds, E. (2002). 'Reconsidering the Labeling Effect for Child Benefits: Evidence from a Transition Economy', Economics Letters 76 (3), 303-09.

Firpo, Sergio, Nicole Fortin and Thomas Lemieux (2007). 'Decomposing Wage Distributions Using Recentered Influence Function Regressions'. Mimeographed document.

Fiszbein, A. and N. Schady (2009). Conditional Cash Transfers: Reducing Present and Future Poverty. Washington, DC, World Bank.

Flores, C. A. and O. A. Mitnik (2009). 'Evaluating Nonexperimental Estimators for Multiple Treatments: Evidence from Experimental Data', Discussion Paper 4451. Bonn, IZA.

Gertler, P. (2004). 'Do Conditional Cash Transfers Improve Child Health? Evidence from PROGRESA's Control Randomized Experiment', American Economic Review 94 (2), 336-341.

Gitter, S. R. and B. Barham (2007). 'Women's Power, Conditional Cash Transfers and Schooling in Nicaragua', StaffPaper Series 517. Agricultural and Applied Economics, University of Wisconsin.

Hahn, J. (1998). 'On the Role of the Propensity Score in Efficient Semiparametric Estimation of Average Treatment Effects', Econometrica 66, 315-331.

Handa, S. and J. A. Maluccio (2010). 'Matching the Gold Standard: Comparing Experimental and Nonexperimental Evaluation Techniques for a Geographically Targeted Program', Economic Development and Cultural Change 58, 415-447.

Handa, S. et al. (2009). 'Opening Up Pandora's Box: The Effect of Gender Targeting and Conditionality on Household Spending Behavior in Mexico's Progresa Program', World Development 37 (6), 1129-1142.

Heckman, J. J., H. Ichimura and P. Todd (1997). 'Matching as an Econometric Evaluation Estimator: Evidence from Evaluating a Job Training Program', Review of Economic Studies 64(4), 605-654.

Heckman, James J., Robert LaLonde and Jeffrey Smith (1999). 'The Economics and Econometrics of Active Labor Market Programs', in O. Ashenfelter and D. Card (eds.), Handbook of Labor Economics v. 3. Amsterdam, North-Holland, 1865-2086.

Hirano, Keisuke and Guido W. Imbens (2001). 'Estimating Causal Effects Using Propensity Score Weighting: An Application to Data on Right Heart Catheterization', Health Services \& Outcomes Research Methodology 2 (3-4), 259-278.

Hirano, Keisuke, Guido W. Imbens and Geert Ridder (2003). 'Efficient Estimation of Average Treatment Effects using the Estimated Propensity Score', Econometrica 71 (4), 1161-1189.

Hoddinott, J. and L. Haddad (1995). 'Does Female Income Share Influence Household Expenditure? Evidence from Cote d'Ivoire', Oxford Bulletin of Economics and Statistics, 57 (1), 77-96.

Hoddinott, J. and E. Skoufias (2004). 'The Impact of PROGRESA on Food Consumption', Economic Development and Cultural Change 53 (1), 37-61.

Horvitz, D. G. and D. J. Thompson (1952). 'A Generalization of Sampling without Replacement from a Finite Universe', Journal of the American Statistical Association 47 (260), 663-685.

Hudgens, M. G. and M. E. Halloran (2008). 'Toward Causal Inference With Interference', Journal of the American Statistical Association 103 (482), 832-842. 
Imbens, G. W. (2000). 'The Role of the Propensity Score in Estimating Dose-Response Functions', Biometrika 87 (3), 706-710.

Juhn, Chinhui, Kevin M. Murphy, Brooks Pierce (1993). 'Wage Inequality and the Rise in Returns to Skill', Journal of Political Economy 101 (3), 410-442.

Kakwani, N. (2000). 'On Measuring Growth and Inequality Components of Poverty with Application to Thailand', Journal of Quantitative Economics 16, 105-118.

Lalive, R. and A. Cattaneo (2009). 'Social Interactions and Schooling Decisions', Review of Economics and Statistics 91 (3), 457-477.

Lechner, M. (2001). 'Identification and Estimation of Causal Effects of Multiple Treatments under the Conditional Independence Assumption', in F. Pfeiffer and M. Lechner (eds.), Econometric Evaluation of Labour Market Policies. Physica-Verlag, Heidelberg, 43-58.

León, M. and S. D. Younger (2007). 'Transfer Payments, Mothers' Income and Child Health in Ecuador', Journal of Development Studies 43 (6), 1126-1143.

Lundberg, S. J., R. A. Pollak and T. J. Wales (1997). 'Do Husbands and Wives Pool Their Resources? Evidence from the United Kingdom Child Benefit', Journal of Human Resources 32 (3), 463-480.

Maluccio, J. A. and R. Flores (2005). 'Impact Evaluation of a Conditional Cash Transfer Program: The Nicaraguan Red de Protección Social', Research Report 141. Washington, DC, International Food Policy Research Institute.

Miguel, Edward and Michael Kremer (2004). 'Worms: Identifying Impacts on Education and Health in the Presence of Treatment Externalities', Econometrica 72 (1), 159-217.

Molyneux, M. (2007). 'Two Cheers for CCTs', IDS Bulletin 38 (3), 69-74.

Oliveira, A. et al. (2007). 'First Results of a Preliminary Evaluation of the Bolsa Família Program', in J. Vaitsman and R. Paes-Sousa (eds.), Evaluation of MDS Policies and Programs Results, v. 2. Brasilia, MDS/SAGI, 19-64.

Paxton, C. and N. Schady (2007). 'Does Money Matter? The Effects of Cash Transfers on Child Health and Development in Rural Ecuador', Policy Research Working Paper 4226. Washington, DC, World Bank.

Ribas, R. P. (2008). 'O Impacto dos Programas de Transferência de Renda sobre Consumo e Preços: A Experiência do Paraguai'. Presented at the Seminário das Quintas, Brasilia, 13 march 2008. DISOC/Ipea.

Robins, J. and A. Rotnizky (1995). 'Semiparametric Efficiency in Multivariate Regression Models with Missing Data', Journal of the American Statistical Association 90 (429), 122-129.

Rosenbaum, P. R. (2007). 'Interference between Units in Randomized Experiments', Journal of the American Statistical Association 102 (477), 191-200.

Rosenbaum, P. R. and Donald B. Rubin (1983). 'The Central Role of the Propensity Score in Observational Studies for Causal Effects', Biometrika 70 (1), 41-55.

Rubalcava, L., G. Teruel and D. Thomas (2004). 'Spending, Saving and Public Transfers Paid to Women', CCPR Working Paper 024-04. California Center for Population Research, UCLA. 
Rubin, D. B. (1977). 'Assignment to Treatment Group on the Basis of a Covariate', Journal of Educational Statistics 2 (1), 1-26.

Rubin, D. B. (1978). 'Bayesian Inference for Causal Effects: The Role of Randomization', Annals of Statistics 6 (1), 34-58.

Rubin, D. B. (1980). 'Discussion of "Randomization Analysis of Experimental Data: The Fisher Randomization Test," by D. Basu', Journal of the American Statistical Association 75, 591-593.

Rubin, D. B. (1986). 'Statistics and Causal Inference', Journal of the American Statistical Association 81 (396), 945-960.

Ruiz-Arranz, M. et al. (2006). 'Program Conditionality and Food Security: The Impact of PROGRESA and PROCAMPO Transfers in Rural Mexico', Revista Economia 7 (2), 249-278.

Schady, N. R. (2006). 'Conditional Cash Transfer Programs: Reviewing the Evidence'. Presented at the Third International Conference on Conditonal Cash Transfers, Istanbul, 26 June 2006.

Schady, N. and J. Rosero (2007). 'Are Cash Transfers Made to Women Spent Like Other Sources of Income?' Policy Research Working Paper 4282. Washington, DC, World Bank.

Schafer, J. L. and N. Schenker (1997). 'Inference with Imputed Conditional Means', Journal of the American Statistical Association 95, 144-154.

Soares, F. V. and R. P. Ribas (2007). Programa Tekoporã - Evaluación del marco lógico, del manual operativo y de la línea base del piloto. Brasilia, International Policy Centre for Inclusive Growth. Mimeographed document.

Soares, F. V., R. P. Ribas and R. G. Osório (2010). 'Evaluating the Impact of Brazil's Bolsa Família: Cash Transfer Programmes in Comparative Perspective', Latin American Research Review, forthcoming.

Sobel, M. E. (2006). 'What do Randomized Studies of Housing Mobility Demonstrate?: Causal Inference in the Face of Interference', Journal of the American Statistical Association 101 (476), 1398-1407.

Thomas, D. (1990). 'Intra-Household Resource Allocation: An Inferential Approach', Journal of Human Resources 25 (4), 635-664.

Wooldridge, Jeffrey M. (2002). 'Inverse Probability Weighted M-estimators for Sample Selection, Attrition and Stratification', Portuguese Economic Journal 1 (2), 117-139.

Wooldridge, Jeffrey M. (2007). 'Inverse Probability Weighted Estimation for General Missing Data Problems', Journal of Econometrics 141 (2), 1281-1301 


\section{NOTES}

1. See Fiszbein and Schady (2009) and Soares et al. (2010) for a review of several impact evaluations of CCT programmes.

2. PROGRESA is now called Oportunidades.

3. Caldes et al. (2006) estimate that 18 per cent of PROGRESA's administrative cost and 2 per cent of total programme cost are due to monitoring conditionality. Moreover, Molyneux (2007) argues that conditionalities also impose indirect costs on beneficiary households, and these costs are eventually paid by mothers more than by other household members.

4. See Flores and Mitnik (2009) for a discussion on the consistency of these multiple treatment estimators.

5. In this paper, household behaviour is considered as collective behaviour derived from aggregate outcomes.

That is, the behavioural change of households represents not only changes in the individual behaviour of their members but also changes in the intra-household bargaining.

6. For a graphical illustration of household decision, see Handa et al. (2009: 1131).

7. They also estimate that 69 per cent of the increase in calories from vegetables is due to the platicas, while the remaining effect is due to the increasing income.

8. Examples of effective results promoted by unconditional cash transfers are given by Duflo (2003),

Agüero et al. (2007), León and Younger (2007), and Paxton and Schady (2007).

9. This characteristic is based on the evidence that women are more benevolent than men in sharing income with their children (Thomas, 1990; Hoddinott and Haddad, 1995; Doss, 2005; Lundberg et al., 1997).

10. Examples of complementary initiatives are the PROGRESA's health talks and family support initiatives like the "family guides" in the case of Tekoporã in Paraguay and social workers' personalised services in Chile Solidario. 11. Since Handa et al. (2009) do not present the result obtained without using instrumental variables, the effect of such variables on the estimation is unknown.

12. Barrera-Osorio et al. (2008) presents other evidence on positive peer effects of CCT programmes on schooling in Colombia.

13. This family support approach is inspired largely by the "psycho-social support" of Chile Solidario's Puente component.

14. In 2009, the minimum benefit was 250,000 guaraníes (US\$ 50) and the maximum was 290,000 (US\$ 58). Currently, each benefit consists of: 80,000 guaraníes from the Bono Alimentario (food grant), which is a fixed amount by family; 35,000 guaraníes for each household member between 0 and 18 years, up to four members; 35,000 guaraníes for households with at least one member older than 65 years; 35,000 guaraníes for households with at least one member with a disability.

15. Initially the programme sought to target only households with an ICV below 25 points, but the realisation that the number of predicted beneficiaries was below the expected numbers per district, and because of some complaints at the local level, the eligibility threshold was increased to 40 points.

16. About 8 per cent of the households registered in the Ficha Hogar had an incomplete interview $(752$ of 9,817$)$. Nonetheless, 98 per cent of these cases (736) were registered by demand and 88 per cent ( 6 from the census and 653 by demand) have been treated (Soares and Ribas, 2007).

17. This statistic is overestimated since it includes hundreds of rejections of households that were located in indigenous communities that could not take part in the programme as it was designed. A specific programme is due to be designed for these communities.

18. The APT parameter can also be interpreted as an ITT parameter.

19. According to Rubin (1977), under similar assumptions, one can obtain estimates for other parameters, such as the average effect of treatment (ATE) and the average effect of treatment on the untreated (ATU), only changing the conditioning of the expectations in equation 4.13.

20. Wooldridge (2002 and 2007) demonstrate the properties of this approach for M estimation in general.

21. In this case, the income component can be called marginal income effect (MIE).

22. Note that our quasi-experimental data, unlike the non-experimental approach of Handa and Diaz (2006) and Handa and Maluccio (2010), comes from the same instrument. Thus it is in line with the best practices regarding the use of propensity score methods - namely, the same questionnaire, comparison group from the same socioeconomic environment, and data collected in the same period for both groups (Heckman et al., 1997). 23. The effect of the programme on expenditure level and composition can only be interpreted as an effect on consumption level and composition if the programme has not affected local prices. Ribas (2008) shows that the Tekoporã has had no significant effect on food prices, considered as the most sensitive to shocks in aggregate demand. These results are available on request.

24. The Ficha Hogar, used as a baseline, lacks information on household consumption. Thus we observe those outcomes only after the programme took place.

25. A further study may include externality as a function of coverage and distance to other beneficiaries. 


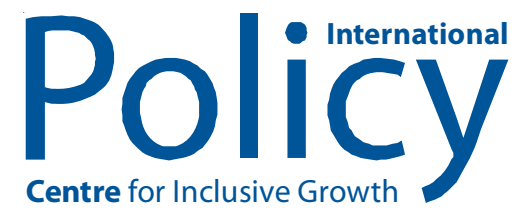

International Policy Centre for Inclusive Growth (IPC - IG)

Poverty Practice, Bureau for Development Policy, UNDP

Esplanada dos Ministérios, Bloco O, $7^{\circ}$ andar

70052-900 Brasilia, DF - Brazil

Telephone: +55 6121055000

E-mail: ipc@ipc-undp.org • URL: www.ipc-undp.org 